DIVISION OF THE HUMANITIES AND SOCIAL SCIENCES

CALIFORNIA INSTITUTE OF TECHNOLOGY

PASADENA, CALIFORNIA 91125

ETHNIC HETEROGENEITY, DISTRICT MAGNITUDE, AND THE NUMBER OF PARTIES

Peter C. Ordeshook

Olga V. Shvetsova

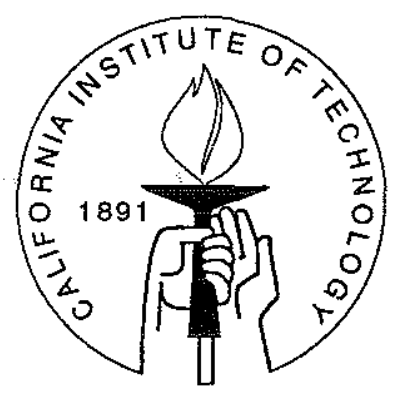

SOCIAL SCIENCE WNORKING PAPER 809

September 1992 


\title{
ETHNIC HETEROGENEITY, DISTRICT MAGNITUDE, AND THE NUMBER OF PARTIES*
}

Peter C. Ordeshook and Olga V. Shvetsova

\begin{abstract}
Recent events leading to the importation of democratic ideas and ideals by previously totalitarian states increase our interest in the ways in which electoral institutions influence party systems. However, even if we restrict our attention to Eastern Europe or the successor states of the Soviet empire, we encounter a range of social diversity - ethnic heterogeneity - that is as great as those in the set of countries examined in earlier studies that seek to identify the influence of electoral laws (c.f., Rae, Lijphart, and Taagepera and Shugart). Curiously, though, these earlier studies fail to ascertain whether and to what extent electoral laws mediate the influence of this heterogeneity. Hence, to develop a more pragmatic understanding of electoral institutions, we adopt the view of electoral laws as intervening structures and, using the data of these earlier analyses, we reconsider the role of one institutional parameter - district magnitude - that some researchers regard as the most important characteristic of an electoral system. Aside from the usual caveats about the limitations of our data, our primary conclusion is that district magnitude is not merely an important determinant of the number of parties that compete in a political system, but that it can offset the tendency of parties to multiply in heterogeneous societies.
\end{abstract}

*This research was supported by grants from The U.S. Institute of Peace and the University of Maryland's IRIS program. The authors also wish to thank John Petrocik and Rod Kiewiet for their many suggestions, and Arend Lijphart for access to his data. 
Ethnic Heterogeneity, District Magnitude, and the Number of Parties

Peter C. Ordeshook and Olga V. Shvetsova

The analysis of political institutions presumes that those institutions mediate between individual preferences and political outcomes, including the nature and number of political parties, public policy, and the stability of the institutions themselves. We also know that preferences have, as one source, society's underlying social structure, especially its ethnic structure. Thus, in ascertaining the influence of institutions on outcomes, we should consider the possibility that similar institutions in different social contexts yield different outcomes. Restated specifically for electoral politics, "[t]he relationship between electoral rules and party systems is not mechanical and automatic: A particular electoral regime does not necessarily produce a particular party system; it merely exerts pressure in the direction of this system ..." (Duverger 1959:40).

This argument, though, is not always made part of our research. Lijphart's (1990) reassessment of Rae's (1971) seminal analysis of electoral laws is a case in point. Lijphart's essential modification is to take periods within a country without "major" changes in electoral structure as the unit of analysis rather than using each election as that unit. However, despite acknowledging that "there are other important causes of multipartism, particularly the number and depth of cleavages in a society" (1990: 488), Lijphart's reanalysis, like Rae, fails to consider Duverger's argument in its full form. The particular problem is that the "usual suspects" examined in these studies, stable democracies, vary greatly in character (compare an ethnically heterogeneous United States with a population of 250 million to homogeneous states such as Iceland and Luxembourg whose combined population fails to exceed that of metropolitan Tulsa). Analyzing the effects of electoral institutions separate from other things ignores the possibility that institutions are intervening structures and that they influence, say, the number of political parties only to the extent that the "more basic" characteristics of a society act through them to increase or decrease this number.

Our interest in understanding the influence of electoral laws derives from those recent events that have led to the importation of democratic ideas and ideals by previously totalitarian states. Even if we restrict our attention to Eastern Europe or the successor states of the Soviet empire, we encounter a range of social diversity that is as great as those in the set of countries examined by Lijphart and Rae. Hence, to develop a more pragmatic understanding of electoral institutions, we adopt the view of electoral laws as intervening structures and we reconsider Rae and Lijphart's analysis of the institutional parameter -- district magnitude -- that some researchers (c.f., Taagepera and Shugart 1989) regard as the most important characteristic of an electoral system. In Section 1 we reconsider the data and some of the variables that are the focus of earlier studies, and in Section 2 we discuss an especially important component of social structure -- ethnic heterogeneity -- that sets the context 
for the operation of electoral institutions in general and district magnitude in particular. In Section 3 we reanalyze matters using Lijphart's approach, whereas in Section 4 we consider Rae's election-byelection method. In Section 5 we use both Rae and Lijphart's approaches to assess the extent to which our conclusions about the joint influence of district magnitude and ethnic heterogeneity depend on the inclusion in the data set of single-member district systems, and in Section 6 we offer some concluding remarks.

\section{Data and Variables}

The Unit of Analysis: Lijphart criticizes Rae's election-by-election approach with the argument that a political system such as the United States, operating under a uniform electoral arrangement throughout this century, ought to be treated as a single observation. Entering all data from the United States along with data from the three French elections held under d'Hondt in 1945 and 1946 biases the analysis in the direction of the consequences of electoral laws as they appear in the U.S. So, after defining an electoral regime to be a period of time in a country in which electoral rules -- the seat allocation formula and the average number of seats to be filled in an electoral district (district magnitude) -- are essentially constant, Lijphart takes regimes as the unit of analysis. The values of other variables, such as the number of parties, are then set equal to their average across all elections within the regime.

Lijphart's argument has at least one theoretically compelling justification that is consistent with his argument for this modification ("elections under the same rules are not really independent cases but merely repeated operations of the same electoral system" p. 482). Specifically, the usual hypotheses about the relationships between the number of parties and electoral laws concern the properties of systems in equilibrium. ${ }^{1}$ Indeed, it is here that we find the justification for excluding data from "unstable" democracies. Hence, an empirical assessment of those hypotheses ought to focus on dependent variables such as "the equilibrium number of parties within a system," and averaging across all elections in a regime moves us closer to this ideal.

This approach, however, can be criticized even if we restrict our attention to stable Western democracies. First, it introduces a bias that is opposite Rae's, because the data includes regimes that entail but a single election. Thus, Lijphart equates the weight of the first post-war (and presumably out-of-equilibrium) French and German elections to all the post-war elections held in, for instance, Canada, the United States, or Australia. Second, although we may predict that a change in electoral law will change the number or strengths of parties, it is not the case that we predict that these changes are instantaneous. Hence, the results of an election immediately following a change may tell us little about the consequences of that change. Third, averaging values of variables within a regime and 
taking these averages as the observations introduces a number of econometric problems, including artificially increasing $\mathrm{R}^{2}$ and $\mathrm{t}$-statistics.

There is no wholly satisfactory methodology since there is no way to learn the "true" equilibrium number of parties in a regime that encompasses, say, two or three elections. Minimally, though, we can do two things. First, we can discard all one-election regimes (Sweden in 1948, Germany in 1949 and 1953, and Israel in 1949). Second, we can set all variables equal to their values in the last election of each regime. But because this approach can be criticized as well (in addition to "wasting" the data from all but the last election of a regime, if changes in electoral laws are endogenous, this last election might actually be an out-of-equilibrium event that signals change), we also consider Rae's original approach and Lijphart's. In this way we assess the extent to which our conclusions depend on our handling of the data.

These adjustments in the treatment of the data bear upon another issue -- the endogeneity of electoral laws. First, we should not be surprised to learn that specific institutional arrangements are chosen because they make life more secure for existing parties and political elites. For example, if single-member districting reduces the incentives of parties to fracture in a multi-ethnic environment, then a system that begins somehow with a small number of parties will maintain and even strengthen that system in the face of increasing heterogeneity to the extent that political elites have control over the rules of a game in which they are successful players. Similarly, if a multiparty system experiences some exogenous shock that threatens to disrupt party structures, then whether that shock changes party structures or whether, through the actions of elites, it results in the change of electoral laws in a way that maintains the status quo will depend on things that we cannot specify here (c.f., Shamir 1985).

Ideally, we prefer to test a theory that specifies $\left[D^{*}(H), N^{*}(H)\right]$, where $D^{*}(H)$ is the equilibrium district magnitude (or any other parameter of an electoral system under investigation) implied by the equilibrium number of parties, $N^{*}(H)$, where $N^{*}(H)$ is a number impled by $D^{*}(H)$, and where $H$ summarizes the permanent characteristics of a society (e.g., ethnic heterogeneity) that influences the relationship between $D^{*}$ and $N^{*}$. Unfortunately, aside from those models that establish [1,2] and [2,2] as equilibria under plurality rule (c.f., Palf rey 1989, Fedderson et al 1990, Cox 1984), we can offer only "reasonable arguments" that $N^{*}$ increases as $D^{*}$ increases and that $\left[D^{*}>2, N^{*}>2\right]$ characterizes whatever other equilibria are possible. ${ }^{2}$ Our analysis, like Rae's and Lijphart's, implicitly assumes that observed values of $D$ correspond to equilibrium values and that changes in $D$ are due to exogenous factors. But our adjustments in the counting of parties within a regime discussed in the next subsection seek a closer approximation to $N^{*}$ than Lijphart or Rae achieve. 
Counting Parties: Although he considers several alternatives, Rae's primary dependent variable is party fractionalization, $F$, based on the Herfindal-Hirschman index and applied to national election returns for the lower house of parliament or legislature. Lijphart and Taagepera and Shugart (1989) calculate the "effective number of parties" by computing $1 /(1-F)$.

The use of this and similar indices stems from the belief that the analyst should not give equal weight to parties that receive, say, sixty versus five percent of the vote. The problem with any fractionalization index, though, is that it obscures the motives and actions of voters and political elites so that it becomes difficult or impossible to discern the effect of institutional structure on these separate motives. For example, suppose that whatever theory we possess predicts (for a given institutional structure and distribution of preferences over policies) that four parties will compete and that each will receive, in equilibrium, an approximately equal vote share. Fractionalization indexes would then measure the extent to which some parties are less than "full fledged" owing to differences in, say, organizational talent. On the other hand, suppose, for some other set of issue preferences, we predict that these four parties continue to compete but that they secure unequal vote shares in equilibrium. A fractionalization index, applied in combination with the observed actual number of parties, may then provide the appropriate measure of the extent to which voter choice matches theoretical expectations. In this instance, if our theory focuses on the incentives of political elites to form and to maintain parties or if it seeks to uncover the interaction of voter and elite motives, then such an index, if used alone, confuses matters by reporting a number less than four or even three.

This problem is like counting the number of breakfast cereals on the market. One approach is to proceed to the local super-market and count; another approach is to compute a fractionalization index using market share data. Which number is correct? If we are interested in learning something about consumer tastes, then a measure of fractionalization may be of some value. But if we seek to gauge the extent to which the cereal market responds to variations in consumer taste or if we wish to compare the responsiveness of this market to others, then simple counts are more appropriate, along with independent measures of tastes. Similarly, unless we assume that all parties gain equal vote shares in equilibrium, application of a fractionalization index can mislead us about the incentives to organize parties. And since the only deductive, mathematically rigorous theory that makes such a prediction concerns special cases -- 1- and 2-member district systems under plurality rule (Palfrey 1984, 1989, Fedderson et al 1990, Cox 1984) -- we should be suspicious of an index that seeks to combine or otherwise distill a complex set of interdependent choices.

In addition, then, to employing "effective number of parties" as a dependent variable, we will also simply count the number of formally organized parties that secure more than one percent of the national vote or one or more seats in the lower house of the legislature. ${ }^{3}$ A one-percent cutoff is 
arbitrary, but it does take us part way toward eliminating "parties" that are mere ephemeral protest movements. In addition, we count only those parties who satisfy this cut-off in two or more successive elections, which has the effect of eliminating those candidates or parties who may receive a significant proportion of the vote in one election but who do not sustain themselves as a separately organized party.

Time Period: Although Rae and Lijphart restrict their attention to post-World War II elections, we should not suppose that the "laws" of electoral competition came into play only after 1945. Elections before World War I may have differed from what followed owing to changes in the franchise; but only because World War II lay in the future is 1918-1939 distinet from the post-World War II period. We see no reason to suppose that the 1935 elections in Britain, for example, are a less valid observation than, say, the German elections of 1949. Consequently, we add the Continental elections in the interval 1918-39 to our data, along with all elections beginning with 1918 that occurred in those countries that held elections throughout the war. ${ }^{4}$ However, when analyzing matters using Lijphart's approach, we assume that 1939-40 (or the pre-war election closest to this date) marked the end of a regime for all countries regardless of the electoral formula that each employed after the war. Finally, we also add post-War election data from Greece, Spain, Portugal, and Japan.

District Magnitude: It is by now agreed in the comparative elections literature that THE critical institutional variable influencing the formation and maintenance of parties is district magnitude -the number of legislative seats to be filled within an electoral district. The importance of magnitude derives, in part, from its influence on the vote quota a party must secure to ensure representation in parliament. Also, magnitude influences a system's proportionality, which also influences the incentives to form and maintain parties: "[district magnitude] affects the proportionality of PR more than do the various mathematical translation formulas ... [and in] this regard the rule of thumb is that the smaller the district the lesser the proportionality and, conversely, the larger the district the greater the proportionality" (Sartori 1986: p. 53).

Unfortunately, characterizing each country by a single measure of magnitude is the source of considerable difficulty. First, few countries with PR have multiple districts that are of uniform magnitude. Second, several such countries also have at-large districts or adjustment seats that are designed specifically to distort or "correct for" the influence of district magnitudes and seat allocation formulas. The most extreme case is Germany, with 249 single-member districts and a single 249member national "district." Owing to this variability, no single measure can capture all aspects of magnitude that appear relevant. Lijphart opts for a simple calculation based on average magnitude. But an average equates a country with $N$ double-member districts to one that has $N / 2$ single-member 
districts plus a single N/2-member "adjustment" or at-large district (e.g., Germany). These two situations do not yield equivalent incentives for party formation, because each can yield a different vote share threshold that parties must meet before they secure legislative representation and because each generates different incentives for voters to vote strategically.

In response to this and similar problems, Lijphart, who uses a simple categorical analysis, accommodates adjustment or at-large seats by moving a country with a "significant" number of such seats into the next larger category of average magnitude. Taagepera and Shugart (1989) offer perhaps the most extensive analysis of "effective" district magnitude and provide a formalized ad justment that seeks to accommodate the fact that legal thresholds or adjustment seats can override the strategic imperatives of a simple average. A wholly theoretically satisfactory justification of their approach, though, requires that: (1) all parties are national; (2) overall variations in district magnitude within a country are not great; and (3) the number of parties, $N$, is approximately equal to district magnitude plus one, $D+1$. Assumptions (1) and (2) are also required to justify using average magnitude. Assumption (3), though, reveals that "effective magnitude" is itself an endogenously determined parameter that is function, in part, of a variable we are attempting to predict. (Moreover, this assumption is not supported by the data.)

The essential problem, here, of course, is that the incentives to form and maintain parties are a complex function of national and district electoral laws, as well as of parliamentary structure. Hence, we know that except for the simplest systems, no single index or measure can summarize the imperatives of most existing electoral laws. Absent a theory that tells us how to convert a description of an electoral system so that we can enter that description into a statistical analysis, we will focus on Rae-Lijphart's calculation of magnitude based on averages. However, in appreciation of the issues they raise, we also examine Taagepera and Shugart's adjustment. ${ }^{5}$ Comparing the performance of these two measures tells us that additional refinements of the calculation of magnitude are likely to be profitable.

\section{Ethnic Heterogeneity}

The study of political institutions assumes that outcomes follow from strategic choices taken as responses to individual preferences and institutional constraints. We have discussed constraints (e.g., district magnitude) and outcomes (e.g., number of political parties). Turning now to preferences, we begin by noting that Taagepera and Shugart (1989), in summarizing Duverger's argument, offer an analysis and a conclusion similar ours, namely that "(1) Plurality rule tends to reduce the number of parties ..., regardless of the number of issue dimensions ... (2) PR Rules tend not to reduce the number of parties, if the number of issue dimensions favors the existence of many parties" (p. 65). However, 
the issue dimensions Taagepera and Shugart count, taken from an earlier study by Lijphart (1984), are specifically substantive and thus can be said to be endogenous to the political system. Since different electoral systems give political elites different incentives to entrepreneur issue salience, we cannot reject the supposition that Taagepera and Shugart's findings are due to the influence of electoral system on issues rather than the effect of issues on outcomes as mediated by electoral system.

What we require, then, is a measure of the exogenous determinants of those preferences that are relevant, a priori, to pressures to increase or decrease the number of political parties. In this respect, a key variable that is of evident contemporary concern is a society's ethnic heterogeneity. We need not review the innumerable essays that document the influence of ethnicity on politics. But, keeping in mind those instances in which political engineering must contend with ethnicity and ethnic conflict when attempting to implement stable democratic systems (c.f., Horowitz 1991), focusing on this characteristic of a society should help us ascertain how alternative electoral laws mediate the influence of ethnic heterogeneity.

There are, though, a number of issues that arise when incorporating ethnic heterogeneity into our analysis: its measurement and the structural form of its incorporation. First, with respect to measurement, we begin by reconsidering our discussion of fractionalization indices. Earlier, we argue against the application of such indices to election returns data, because it confuses the interdependent motives and actions of voters and political elites. But social heterogeneity (with the possible exception of religion) is not a product of individual choice -- rather, it is better portrayed as an exogenously determined social state. And an especially convenient characterization of heterogeneity is the probability that two randomly chosen individuals are of the same ethnic group. Hence, if there are valid arguments that such indices measure anything, then they apply to ethnicity. ${ }^{6}$ Thus, one indicator of ethnic heterogeneity is simply ethnic fractionalization, $F$, where $F$ varies between 0 and 1 and denotes the ethnic (linguistic, religious) fractionalization of society (where 1 , the upper limit of fractionalization, is approached when every individual is a member of a different group).

Notice now that $F$ admits two measures that can be entered into a regression analysis -- $F$ itself, and $H=1 /(1-F)$. This second variable, $H$, measures the "effective number of ethnic groups" in the same way as Lijphart calculates "effective number of parties" from Rae's fractionalization measure. However, in lieu of arguing whether $F$ or $H$ is more theoretically satisfying (we believe that $H$ is the more appropriate calculation for the reasons that Lijphart and Taagepera and Shugart offer), we note simply that in the regressions reported in this essay, $H$ uniformly provides better fits than does $F$.

Of course, as with most other things, no single index can serve as a wholly satisfactory measure of every aspect of social heterogeneity that we might think is relevant. For example, separate indexes for ethnic, religious, and linguistic heterogeneity might be employed in recognition of the fact that 
ethnic heterogeneity is but one potential dimension of social cleavage. Although we focus on ethnicity, because we have more confidence in its measurement and the resulting index of fractionalization, ${ }^{7}$ our problems do not end even if we employ separate indexes (see note 12 for consideration of religious and linguistic heterogeneity).

First, separate indexes would not tell us whether and to what extent these cleavages correlate. A society may have two ethnic and two religious groups, but anywhere from two to four distinct ethnicreligious clusters depending on the extent to which these cleavages are cross-cutting. Second, a fractionalization index cannot tell us much about the salience of these cleavages, which is not only endogenous, but, as events in Belgium reveal, can change and can greatly influence party structures (Lijphart 1977, Rabushka and Shepsle 1972). Finally, a fractionalization index ignores the important matter of territoriality. The particular problem is that ethnic, religious, and linguistic heterogeneity can operate differently when groups are geographically separate than when all groups are mixed (c.f., Horowitz 1985, 1991). Territoriality allows for a heterogeneous society but homogeneous election districts and thereby places can influence the incentives of parties to compete within a district and nationally. Thus, although Switzerland and the U.S. are both ethnically heterogeneous, the relative absence of territorial considerations in the U.S. as compared to the situation in Switzerland suggests that even if both countries adopted identical electoral laws, heterogeneity and those laws would operate differently in each country. ${ }^{8}$

At this point, though, we must confront the fact that even if we were to identify theoretically appropriate measures of all potentially relevant variables and their functional relationships, we would soon exhaust our degrees of freedom. There are many more potential permutations of social and institutional structures than would exist in any data set. However, our purpose here is not to ascertain precisely how ethnic heterogeneity influences party systems. Rather, we merely want to determine whether the influence of a single institutional variable, district magnitude, on the number of political parties is better described if we take a simple characterization of society's ethnic structure into account, with the understanding that there is considerable room for additional refinements in the conceptualization and measurement of variables.

So suppose that we have an index, $H$, that we take to measure the effective number of ethnic groups. ${ }^{9}$ Our next question is how to enter this variable into the analysis. That is, if the number of political parties, $N$, is a function of $H$ as well as of electoral laws, $L$, then we must contemplate alternative functional forms. Regardless of how $L$ and $H$ are conceptualized or operationalized, there are two primary choices. The first choice assumes that heterogeneity and election law have independent effects modeled by the simple linear relationship

$$
N=\alpha+b_{1} L+b_{2} H \text {. }
$$


This expression, then, permits district magnitude, heterogeneity, or both variables simultaneously to have no effect on party competition. The second possibility is the one that is more consonant with the hypothesis that heterogeneity's impact is mediated by electoral structure -- or, equivalently, that the operation of electoral structure depends on fixed social preconditions. This possibility is modeled by the multiplicative relationship

$$
N=\alpha+8 L^{*} H
$$

This second expression, then, models Taagepera and Shugart's (1989:65) revision of Duverger's hypothesis. However, rather than rely as they do on subjective counts of election issues -- the salience of which are almost certainly endogenously determined -- we operationalize $H$ as a variable that cannot itself be influenced by electoral law. This is not to say that the salience of issues related to ethnicity are not endogenous. Indeed, we should assume that they are related, since the dependence of salience on institutional structure is part of the role institutions play in intervening between outcomes and social structure. Instead, $H$ measures the potential salience of ethnicity as a basis for party formation.

The analysis we report here, then, ascertains which of these two functional forms best describes the data that are the focus of Rae and Lijphart's research and whether incorporating ethnic heterogeneity into the analysis contributes anything to our understanding of the consequences of electoral laws. Before proceeding, though, we note that Sartori (1986: 67, fn 15) of fers the reasonable argument that the relationship between proportionality and district magnitude and, by inference, between number or parties and magnitude, is curvilinear. That is, although we might predict that single-member districts imply 2-party systems, and that, say, 15-member districts might allow four or five parties, it is unreasonable to suppose that 120- or 150-member districts (Israel and the Netherlands) will generate thirty or forty parties, ceteris paribus. Consequently, in addition to considering district magnitude, $D$, by itself, we also consider $D^{1 / 2}$ and the natural $\log$ of $D, \ln (D) .{ }^{10}$

Notice now that comparing $\ln (D)$ to $D$ and $D^{1 / 2}$ is especially useful. Since $\ln (1)=0$, letting $L=$ $\ln (D)$ in expression (2) is equivalent to assuming that heterogeneity is of no consequence in singlemember district systems whereas using $D$ and $D^{1 / 2}$ allows heterogeneity to "operate" even in those systems. Thus, if, after completing our empirical analysis, we have more confidence in employing $\ln (D)$ in expression (2) than we have in the alternatives, then we should tentatively accept the hypothesis that single-member district systems suppress and even eliminate the potential divisive effects of ethnic heterogeneity (c.f., Horowitz 1990). Indeed, this finding, reported in the next section, is strong evidence in support of Taagepera and Shugart's previously cited restatement of Duverger's argument. 


\section{Analysis -- Lijphart's Regime Approach}

Beginning with Lijphart's regime data, Table 1 presents a series of regressions in which the dependent variable is the "effective number of parties" based on each party's share of the vote (ENPV) as calculated by Lijphart. Clearly, none of the results this table reports are statistically spectacular, but notice first, from regressions $1-3$, that $\ln (D)$ performs better than $D$ or $D^{1 / 2}$, although district magnitude's ef fect on ENPV is signif icant regardless of how it is entered. Second, regression 4 reveals that ethnic heterogeneity alone is statistically unrelated to ENPV. Third, the comparison of regressions 1 and 6 reveals that adding $H$ to a regression that already contains $\ln (D)$ also contributes nothing to predictive power -- indeed, due to a loss of degrees of freedom, adjusted $\mathrm{R}^{2}$ declines. Thus, if we assume an additive specification like expression (1), the best fit and the most parsimonious model using Lijphart's data is simply $E N P V=3.24+.34 \ln (D) .{ }^{11}$ That is, adherence to an additive structure that leads to the conclusion that the effective number of ethnic groups has no influence on ENPV and that $\ln (D)$ provides whatever explanatory power is available in the two independent variables this study considers.

Table 1: Dependent Variable $=E N P V$, Lijphart's Data $(n=32)$

\begin{tabular}{|c|cccccccc|}
\hline reg. \# & 1 & 2 & 3 & 4 & 5 & 6 & 7 & 8 \\
\hline Const. & 3.68 & 3.39 & 3.24 & 4.10 & 3.47 & 3.10 & 3.35 & 3.16 \\
& $(18.4)$ & $(14.2)$ & $(12.5)$ & $(13.2)$ & $(9.7)$ & $(7.0)$ & $(14.1)$ & $(12.9)$ \\
$D$ & .01 & - & - & - & - & - & - & - \\
& $(4.6)$ & & & & & & & \\
$D^{1 / 2}$ & - & .14 & - & - & .14 & - & - & - \\
& & $(4.1)$ & & & $(4.1)$ & & & \\
$\ln (D)$ & - & - & .34 & - & - & .36 & - & - \\
& & & $(3.5)$ & & & $(3.3)$ & & \\
$H$ & - & - & - & -.19 & -.05 & .09 & - & - \\
& & & & $(-.87)$ & $(-.25)$ & $(.41)$ & & \\
$H^{*} D^{1 / 2}$ & - & - & - & - & - & - & 0.13 & - \\
& & & & & & & $(4.1)$ & \\
$H \ln (D)$ & - & - & - & - & - & - & - & .33 \\
& & & & & & & & $(4.1)$ \\
\hline adj. R ${ }^{2}$ & .08 & .12 & .17 & .001 & .09 & .15 & .14 & .25 \\
$\mathrm{~F}-\mathrm{stat}$. & 2.6 & 4.1 & 6.1 & 0.1 & 1.43 & 2.56 & 4.88 & 10.0 \\
\hline
\end{tabular}


The last regression in this table, though, shows that this conclusion is erroneous. Specifically, the best overall fit is secured assuming, in accordance with expression (2), that heterogeneity and district magnitude are interactive. Moreover, the comparison of regressions 7 and 8 shows that, at least when ENPV is our dependent variable, the best model is one in which ethnic heterogeneity is assumed to have no effect on the number of political parties in single-member district systems. ${ }^{12}$

The comparison of regressions 3 and 8 is also interesting with respect to this conclusion. Notice in particular that although the coefficient on $\ln (D)$ in 3 is significant and nearly identical to that on $H^{*} \ln (D)$ in 8 , multiplying $\ln (D)$ by the effective number of ethnic groups increases $\mathrm{R}^{2}$ from $17 \%$ to 25\%. That is, although our qualitative conclusion about the influence of district magnitude on the number of parties does not change with how $\ln (D)$ is entered into a regression, the "quality" of that regression improves if we treat district magnitude as a variable that intervenes between ethnic heterogeneity and the effective number of parties.

Countries and Time Period: What we must now do is ascertain the robustness of this finding against various things, including: (1) the countries and election periods under consideration; (2) the method of counting the number of parties; and (3) alternative measures of district magnitude. First, then, accepting the possibility that averages across regimes admit of too many out-of-equilibrium elections, consider Table 2, which takes the regimes defined by Lijphart, extends the time period to 1990 , but takes only the last election in each regime as the observation corresponding to that regime. In addition, regressions $11-14$ delete those regimes that contain only one election; and regressions 13 and 14 add the data from Japan, Spain, Portugal, and Greece, as well as data from the last pre-War regime.

Because we are no longer averaging variables within regimes, statistical relationships appear weaker in regression 9-12 than in 6 and 8 -- their counterparts in Table 1. Excluding 1-election regimes improves the fit (regressions 11 and 12), but not to the same extent as does adding excluded countries and pre-war elections (regressions 13 and 14). Indeed, the results using the full data set (regressions 13 and 14), which includes countries that Lijphart excludes owing to their recent arrival upon the democratic scene, produces results that are essentially identical to those that regressions 6 and 8 report. Most importantly, though, we see that our earlier conclusion about the superiority of an interactive model as against a linear-additive model is robust to manipulations of the data under consideration. That is, comparing regressions 9 and 10, 11 and 12, or 13 and 14 shows that adjusted $\mathrm{R}^{2}$ increases significantly if $H$ and $\ln (D)$ are treated as a multiplicative variable rather than as separate independent variables. 
Table 2: Dependent Variable $=E N P V$, using last election only from a regime

\begin{tabular}{|c|cccccc|}
\hline regression \# & 9 & 10 & 11 & 12 & 13 & 14 \\
\hline \multirow{2}{*}{ constant } & 3.33 & 3.5 & 3.08 & 3.4 & 2.75 & 3.0 \\
& $(4.3)$ & $(13.3)$ & $(3.7)$ & $(12.6)$ & $(5.4)$ & $(15.3)$ \\
$\ln (D)$ & .27 & - & .31 & - & .45 & - \\
& $(2.0)$ & & $(2.0)$ & & $(3.5)$ & \\
$H$ & .27 & - & .35 & - & .27 & - \\
& $(0.5)$ & & $(0.6)$ & & $(0.9)$ & \\
$H^{*} \ln (D)$ & - & .31 & - & .35 & - & .43 \\
& & $(2.6)$ & & $(2.4)$ & & $(4.0)$ \\
\hline \multirow{2}{*}{ adj. $R^{2}$} & .02 & .15 & .02 & .17 & .14 & .27 \\
F-statistic & 0.3 & 5.6 & 0.3 & 5.7 & 3.98 & 18.5 \\
$n$ & 34 & 34 & 30 & 30 & 52 & 52 \\
\hline
\end{tabular}

Counting Parties: Now let us consider other operationalizations of "number of parties." Table 3, using the full data set (but once again, excluding 1-election regimes) reproduces regressions 13 and 14 along with regressions in which effective number of parties is calculated using seats (ENPS) and in which we count parties that receive at least $1 \%$ of the vote in two or more successive elections $(N V)$ or that secure one or more seats in at least two successive elections (NS).

The regressions this table reports warrant at least three comments. First, an interactive relation remains superior to a simple linear additive one regardless of our choice of dependent variable. Thus, our conclusion about how heterogeneity ought to be entered into the analysis -- as a variable that mediates the influence of district magnitude -- is invariant with how we choose to count parties. Second, the best overall fit occurs when we simply count the number of parties. Thus, even if we substitute, say, Molinar's (1991) modification of fractionalization (which in general gives a higher count of number of effective parties than does Lijphart's measure but which correlates nearly perfectly with ENPV otherwise), a simple count of parties is the more accurately predicted dependent variable.

Our final comment concerns the explanatory power gained by adding $H$ to the analysis. Briefly, if we delete $H$ altogether from the analysis and simply regress $E N P V, E N P S, N V$, and $N S$ on $\ln (D)$ alone, then adjusted $\mathrm{R}^{2}$ declines from $.25, .31, .39$, and .36 to $.14, .21, .30$, and .29 , respectively. Thus, although average district magnitude "contributes" more to the determination of these alternative ways of counting parties than does $H$, the inclusion of $H$ refines the relationship between $\ln (D)$ and these counts. ${ }^{13}$ 
Table 3: Alternative counting of parties (last election only, full data set, $n=52$ )

\begin{tabular}{|c|c|c|c|c|c|c|c|}
\hline $\begin{array}{c}\text { reg. } \\
\#\end{array}$ & $\begin{array}{l}\text { dep. } \\
\text { var. }\end{array}$ & const. & $\ln (D)$ & $H$ & $H^{*} \ln (D)$ & $\operatorname{adj} \cdot R^{2}$ & F-stat. \\
\hline 13 & $E N P V$ & $\begin{array}{c}2.7 \\
(5.4)\end{array}$ & $\begin{array}{c}45 \\
(3.5)\end{array}$ & $\begin{array}{c}27 \\
(0.9)\end{array}$ & - & .14 & 3.98 \\
\hline 14 & $E N P V$ & $\begin{array}{c}3.0 \\
(15.3)\end{array}$ & - & - & $\begin{array}{c}.43 \\
(4.0)\end{array}$ & .27 & 18.49 \\
\hline 15 & ENPS & $\begin{array}{l}2.42 \\
(5.3)\end{array}$ & $\begin{array}{c}.47 \\
(4.4)\end{array}$ & $\begin{array}{l}.12 \\
(.43)\end{array}$ & - & .20 & 6.13 \\
\hline 16 & ENPS & $\begin{array}{c}2.48 \\
(15.5)\end{array}$ & - & - & $\begin{array}{c}.44 \\
(5.1)\end{array}$ & .33 & 24.63 \\
\hline 17 & $N V$ & $\begin{array}{l}3.82 \\
(4.6)\end{array}$ & $\begin{array}{l}1.06 \\
(5.1)\end{array}$ & $\begin{array}{c}.20 \\
(0.5)\end{array}$ & - & .29 & 10.00 \\
\hline 18 & $N V$ & $\begin{array}{c}3.98 \\
(10.3)\end{array}$ & - & - & $\begin{array}{c}.94 \\
(6.5)\end{array}$ & .40 & 33.33 \\
\hline 19 & $N S$ & $\begin{array}{c}3.49 \\
(3.60)\end{array}$ & $\begin{array}{l}1.23 \\
(5.3)\end{array}$ & $\begin{array}{c}.42 \\
(.90)\end{array}$ & - & .28 & 9.52 \\
\hline 20 & $N S$ & $\begin{array}{c}4.02 \\
(8.60)\end{array}$ & - & - & $\begin{array}{c}1.04 \\
(6.30)\end{array}$ & .36 & 28.13 \\
\hline
\end{tabular}

District Magnitude: Tables 2 and 3 give us confidence that our conclusion about the superiority of an interactive model is robust to manipulations in the countries and time period considered and to the operationalization of our dependent variable, we should also consider alternative measures of district magnitude. We have noted already that no single measure can capture all of the variation in election systems. Nevertheless, let us consider the measure that Taagepera and Shugart (1989) propose in order to take more explicit account of the vote thresholds that parties must achieve before securing legislative or parliamentary representation owing either to legally specified thresholds or to adjustment seats and at-large districts that move a system closer to proportionality. Table 4, then, reproduces the regressions reported in Table 3, except that now we replace the calculation of $D$ based on a simple average with Taagepera and Shugart's calculations of "effective magnitude," $D_{\mathrm{e}} \cdot{ }^{14}$

The comparison of Tables 3 and 4 shows that, with the exception of the variable $N S$, Taagepera and Shugart's measure does in fact perform better than does $D$, the simple average. ${ }^{15}$ Looking at the interactive model, and comparing regressions 14,16 , and 18 with regressions 22,24 , and $26, \mathrm{R}^{2}$, $\mathrm{s}$ increase from $.27, .33$, and .40 to $.36, .46$, and .44 , respectively for the dependent variables $E N P V$, $E N P S$, and $N V$. Thus, although we continue to use $D$ in our reanalysis of Rae's approach in the next 
section, Taagepera and Shugart's efforts at devising a more theoretically satisfying measure of district magnitude warrant closer attention, because additional refinements may generate additional payoff.

Table 4: "Effective" district magnitude $(n=52)$

\begin{tabular}{|c|c|c|c|c|c|c|c|}
\hline $\begin{array}{c}\text { reg. } \\
\#\end{array}$ & $\begin{array}{l}\text { dep. } \\
\text { var. }\end{array}$ & const. & $\ln \left(D_{\mathrm{e}}\right)$ & $H$ & $H^{*} \ln \left(D_{\mathrm{e}}\right)$ & $\operatorname{adj} \cdot R^{2}$ & F-stat. \\
\hline 21 & $E N P V$ & $\begin{array}{c}2.14 \\
(3.6)\end{array}$ & $\begin{array}{c}53 \\
(4.3)\end{array}$ & $\begin{array}{c}.47 \\
(1.3)\end{array}$ & - & .21 & 6.51 \\
\hline 22 & $E N P V$ & $\begin{array}{c}2.69 \\
(13.4)\end{array}$ & - & - & $\begin{array}{c}.49 \\
(5.2)\end{array}$ & .36 & 28.13 \\
\hline 23 & ENPS & $\begin{array}{l}1.73 \\
(3.3)\end{array}$ & $\begin{array}{c}.57 \\
(5.7)\end{array}$ & $\begin{array}{c}.35 \\
(1.1)\end{array}$ & - & .30 & 10.50 \\
\hline 24 & ENPS & $\begin{array}{c}2.14 \\
(14.1)\end{array}$ & - & - & $\begin{array}{c}.51 \\
(6.8)\end{array}$ & .46 & 42.60 \\
\hline 25 & $N V$ & $\begin{array}{c}2.99 \\
(2.90)\end{array}$ & $\begin{array}{l}1.09 \\
(4.6)\end{array}$ & $\begin{array}{c}.50 \\
(1.0)\end{array}$ & - & .30 & 10.50 \\
\hline 26 & $N V$ & $\begin{array}{l}3.54 \\
(8.4)\end{array}$ & - & - & $\begin{array}{c}.98 \\
(6.3)\end{array}$ & .44 & 39.29 \\
\hline 27 & $N S$ & $\begin{array}{l}2.97 \\
(2.4)\end{array}$ & $\begin{array}{l}1.13 \\
(3.8)\end{array}$ & $\begin{array}{c}.63 \\
(1.1)\end{array}$ & - & .23 & 7.32 \\
\hline 28 & $N S$ & $\begin{array}{l}3.73 \\
(6.8)\end{array}$ & - & - & $\begin{array}{l}1.00 \\
(5.0)\end{array}$ & .34 & 25.76 \\
\hline
\end{tabular}

What we want to emphasize, though, is that our conclusion about the superiority of the interactive structure that models district magnitude as an intervening parameter does not depend on how we operationalize district magnitude. First, and as before, regressions 22, 24, 26, and 28 each yields a better fit than its additive counter-part. And second, aside from the data that Table 4 reports, if we regress $E N P V, E N P S, N V$, and $N S$ on $\ln \left(D_{\mathrm{e}}\right)$ alone rather than $H^{*} \ln \left(D^{\mathrm{e}}\right)$, adjusted $\mathrm{R}^{2}$ 's decline to .18, $.29, .30$, and .23 from $.34, .43, .43$, and .34 , respectively.

\section{A Brief Reconsideration of Rae's Approach}

Before putting any "seal of approval" on the interactive model, we must consider a number of additional issues: First; we should consider Rae's election -by=election data in order to be certain that our conclusions do not depend on definitions of a regime or on regimes that survive for only a few elections. Second, noting that countries with single-member district procedures, on average, are more heterogeneous that are those with PR systems, we want to be certain that it is not the non-PR 
countries (Australia, the United States, the United Kingdom, New Zealand, Canada, and France after 1958) that provide the sole source of explanatory power.

Turning first to Rae's approach of taking each election outcome as an independent observation, Table 5 of fers the relevant regressions, and once again of fers a comparison of additive and interactive models for the alternative dependent variables. Perhaps the most important fact to be gleaned from these regressions is that our qualitative conclusion is sustained -- the interactive model performs better than a linear additive one. Not only does Table 5 repeat the pattern of better overall fits for the interactive model than the simple additive one, regardless of dependent variable, but the use of $H^{*} \ln (D)$ once again generates an improvement in fit over the use of $\ln (D)$ alone -- $\mathrm{R}^{2}$ s increase from $.33, .40, .42$, and .44 to $.38, .44, .47$, and .49 .

Table 5: Election-by-Election Data, full sample $(n=453)$

\begin{tabular}{|c|c|c|c|c|c|c|c|}
\hline $\begin{array}{c}\text { reg. } \\
\#\end{array}$ & $\begin{array}{l}\text { dep. } \\
\text { var. }\end{array}$ & const. & $\ln (D)$ & $H$ & $H^{*} \ln (D)$ & $\operatorname{adj} . R^{2}$ & $F$-stat \\
\hline 29 & $E N P V$ & $\begin{array}{c}2.7 \\
(20.6)\end{array}$ & $\begin{array}{c}.55 \\
(14.1)\end{array}$ & $\begin{array}{c}.10 \\
(1.5)\end{array}$ & - & .33 & 110.8 \\
\hline 30 & $E N P V$ & $\begin{array}{c}2.8 \\
(50.5)\end{array}$ & - & - & $\begin{array}{c}.45 \\
(15.5)\end{array}$ & .38 & 276.4 \\
\hline 31 & ENPS & $\begin{array}{c}2.37 \\
(20.6)\end{array}$ & $\begin{array}{c}.57 \\
(16.3)\end{array}$ & $\begin{array}{c}.04 \\
(0.7)\end{array}$ & - & .40 & 150,0 \\
\hline 32 & ENPS & $\begin{array}{c}2.43 \\
(52.2)\end{array}$ & - & - & $\begin{array}{c}.47 \\
(18.1)\end{array}$ & .44 & 354.4 \\
\hline 33 & $N V$ & $\begin{array}{c}3.35 \\
(14.5)\end{array}$ & $\begin{array}{c}1.20 \\
(18.7)\end{array}$ & $\begin{array}{c}.21 \\
(2.00)\end{array}$ & - & .43 & 160.7 \\
\hline 34 & $N V$ & $\begin{array}{c}3.69 \\
(35.6)\end{array}$ & - & - & $\begin{array}{c}.96 \\
(20.9)\end{array}$ & .47 & 399.9 \\
\hline 35 & $N S$ & $\begin{array}{c}2.54 \\
(9.80)\end{array}$ & $\begin{array}{c}1.49 \\
(19.8)\end{array}$ & $\begin{array}{c}.52 \\
(4.30)\end{array}$ & - & .45 & 184.1 \\
\hline 36 & $N S$ & $\begin{array}{c}3.4 \\
(29.5)\end{array}$ & - & - & $\begin{array}{c}1.16 \\
(21.1)\end{array}$ & .49 & 433.3 \\
\hline
\end{tabular}

Aside from the fact that $\mathrm{R}^{2}$, s are higher in Table 5 than in Table 3 (which is to be expected owing to the greater number of observations -- 52-versus 453), the only difference of note is that the coefficient on heterogeneity is significant when $N V$ and $N S$ are the dependent variables and when heterogeneity is treated as a separate independent variable (regressions 41 and 43). However, when the interactive model is considered, the similarities between Tables 3 and 5 in the magnitudes of 
coefficients are more remarkable. Looking at the coefficient on $H^{*} \ln (D)$, if we use Lijphart's regime approach, we get $.43, .44, .94$, and 1.04 for each of the four dependent variables (regressions 14, 16, 18 , and 20) whereas if we use election-by-election data we get $.45, .47, .96$, and 1.16 (regressions 30 , 32,34 , and 36 ) -- an average difference of less than $7 \%$. Thus, once heterogeneity is appropriately factored into the analysis, there is no reason to modify Rae's original conclusions about the influence of district magnitude or to argue that district magnitude has a different influence on party systems when regimes rather than individual elections are taken as the unit of analysis.

\section{PR Systems Only}

The last issue we want to address concerns the extent to which our results are driven by the fact that the most heterogeneous states on average are those with single-member districts and with the fewest number of parties. Specifically, those countries with single-member district regimes -- the United States, Canada, Australia, Great Britain, New Zealand, and France -- are, on average, more heterogeneous than their proportional-representation counterparts (with an average fractionalization score of .40 versus .15) and are associated, on average, with lower values of ENPV (2.98 versus 4.48 for the most recent regime). The particular hypothesis we want to examine, then, is Taagepera and Shugart's (1989:142) assertion that "the decisive question is not whether a particular system is plurality or PR, but what its effective magnitude is."

Tables 6 and 7, then, report the results of a series of regressions that parallel those in Tables 3 and 5 , except that Tables 6 and 7 only use data from PR systems. As expected, the significance of heterogeneity alone increases and the gap in goodness of fit as measured by $R^{2}$ between the liner and interactive specifications narrows or disappears altogether, especially when parties are simply counted (when the dependent variable is $N V$ or $N S$ ). Of course, since the use of expression (2) entails the estimation of only two variables rather than three, the $F$-statistics for the interactive model are greater than for the additive model. Aside from this difference, though, it appears that the advantage of the interactive model over the additive one disappears in PR systems. That is, the evident superiority of the interactive model appears to derive solely from the fact that single-member district states not only have fewer parties on average, but also are more heterogeneous than their PR counterparts.

Nevertheless, these data do support the hypothesis that district magnitude is best modeled as an intervening variable. Looking first at the intercept terms, if we use the interactive model, then the average absolute difference between the value of this term for the complete and partial data sets is .29 and .30; but if we use the additive model, this difference is 2.13 and 1.06 for the regime and election-by-election data, respectively. Similarly, while the coefficient on $\ln (D)$ when used in the 
additive model varies on average by .19 and .12 in the two data sets (or $25 \%$ and $14 \%$ of the overall average), the coefficient on $H^{*} \ln (D)$ varies by .09 and .08 (or $14 \%$ and $11 \%$ of the overall average). Thus, the interactive model offers estimates that are less sensitive to the treatment of the data.

Table 6: Regime Data, PR systems only $(n=40)$

\begin{tabular}{|c|c|c|c|c|c|c|c|}
\hline $\begin{array}{c}\text { reg. } \\
\#\end{array}$ & $\begin{array}{l}\text { dep. } \\
\text { var. }\end{array}$ & const. & $\ln (D)$ & $H$ & $H^{*} \ln (D)$ & $\operatorname{adj} \cdot R^{2}$ & F-stat \\
\hline 37 & $E N P V$ & $\begin{array}{l}1.14 \\
(1.4)\end{array}$ & $\begin{array}{c}.23 \\
(1.7)\end{array}$ & $\begin{array}{l}2.07 \\
(2.8)\end{array}$ & - & .26 & 6.5 \\
\hline 38 & $E N P V$ & $\begin{array}{l}3.10 \\
(8.5)\end{array}$ & - & - & $\begin{array}{c}.40 \\
(2.6)\end{array}$ & .14 & 6.2 \\
\hline 39 & ENPS & $\begin{array}{l}1.20 \\
(1.6)\end{array}$ & $\begin{array}{c}.22 \\
(1.9)\end{array}$ & $\begin{array}{l}1.70 \\
(2.7)\end{array}$ & - & .22 & 5.2 \\
\hline 40 & ENPS & $\begin{array}{l}2.81 \\
(8.7)\end{array}$ & - & - & $\begin{array}{c}.34 \\
(2.8)\end{array}$ & .12 & 5.2 \\
\hline 41 & $N V$ & $\begin{array}{l}1.38 \\
(1.4)\end{array}$ & $\begin{array}{c}.88 \\
(4.5)\end{array}$ & $\begin{array}{l}2.66 \\
(2.7)\end{array}$ & - & .28 & 7.2 \\
\hline 42 & $N V$ & $\begin{array}{l}4.09 \\
(7.6)\end{array}$ & - & - & $\begin{array}{c}.91 \\
(5.2)\end{array}$ & .28 & 14.8 \\
\hline 43 & $N S$ & $\begin{array}{c}.20 \\
(.15)\end{array}$ & $\begin{array}{r}1.33 \\
(6.8)\end{array}$ & $\begin{array}{l}2.94 \\
(2.6)\end{array}$ & - & .35 & 10.0 \\
\hline 44 & $N S$ & $\begin{array}{l}3.39 \\
(6.6)\end{array}$ & - & - & $\begin{array}{l}1.23 \\
(7.3)\end{array}$ & .36 & 21.4 \\
\hline
\end{tabular}

There are some things, moreover, that do not change when we delete single-member district systems from the sample. First, better fits continue to be secured when parties are simply counted rather than computed on the basis of a fractionalization index. Thus, a simple count is more predictable than a measure of the effective number of parties, regardless of whether we include single-member district systems. Second, the estimated coefficients for $H^{*} \ln (D)$ do not change dramatically -- to $.40, .34, .91$, and 1.23 from $.43, .44, .94$, and 1.04 for the regime data and to .39 , $.38, .89$, and 1.26 from $.45, .47, .96$, and 1.16 with election-by-election data. Once again, then, these numbers show a considerable stability across alternative treatments of the data.

Overall, then, we can see that much of the evidence in favor of an interactive-model does in fact derive from the character of single-member district states. However, we cannot be altogether indifferent between models even if we restrict our attention to PR systems. Considerations like parsimony, F-statistics, and the stability of coefficients lead us to prefer estimations in the form of 
expression (2) over expression (1). And although we can reason that the choice between single- and multi-member district systems is a qualitative one that entails other decisions such as the weight that ought to be given to achieving proportional representation in some form, analyzing the effects of district magnitude can proceed under Taagepera and Shugart's (1989) argument that single-member district systems are quantitatively but not qualitatively different form their multi-member district counterparts.

Table 7: Election-by-Election Data, PR systems only $(n=318)$

\begin{tabular}{|c|c|c|c|c|c|c|c|}
\hline $\begin{array}{c}\text { reg. } \\
\#\end{array}$ & $\begin{array}{l}\text { dep. } \\
\text { var. }\end{array}$ & const. & $\ln (D)$ & $H$ & $H^{*} \ln (D)$ & $\operatorname{adj} . R^{2}$ & F-stat \\
\hline 45 & $E N P V$ & $\begin{array}{l}2.11 \\
(7.8)\end{array}$ & $\begin{array}{c}.41 \\
(8.4)\end{array}$ & $\begin{array}{c}.90 \\
(3.0)\end{array}$ & - & .21 & 41.8 \\
\hline 46 & $E N P V$ & $\begin{array}{c}3.06 \\
(28.7)\end{array}$ & - & - & $\begin{array}{c}.39 \\
(9.4)\end{array}$ & .21 & 84.0 \\
\hline 47 & ENPS & $\begin{array}{l}1.90 \\
(7.6)\end{array}$ & $\begin{array}{c}.43 \\
(9.2)\end{array}$ & $\begin{array}{c}.75 \\
(3.6)\end{array}$ & - & .21 & 41.8 \\
\hline 48 & ENPS & $\begin{array}{c}2.73 \\
(26.1)\end{array}$ & - & - & $\begin{array}{c}.38 \\
(9.8)\end{array}$ & .21 & 84.0 \\
\hline 49 & $N V$ & $\begin{array}{l}2.13 \\
(4.7)\end{array}$ & $\begin{array}{c}1.01 \\
(12.6)\end{array}$ & $\begin{array}{l}1.62 \\
(4.4)\end{array}$ & - & .30 & 67.5 \\
\hline 50 & $N V$ & $\begin{array}{r}3.95 \\
(20.1)\end{array}$ & - & - & $\begin{array}{c}.89 \\
(13.3)\end{array}$ & .30 & 135.4 \\
\hline 51 & $N S$ & $\begin{array}{c}.58 \\
(1.2)\end{array}$ & $\begin{array}{c}1.48 \\
(17.3)\end{array}$ & $\begin{array}{l}2.13 \\
(4.9)\end{array}$ & - & .41 & 109.7 \\
\hline 52 & $N S$ & $\begin{array}{r}3.05 \\
(16.2)\end{array}$ & - & - & $\begin{array}{c}1.26 \\
(17.6)\end{array}$ & .40 & 210.7 \\
\hline
\end{tabular}

\section{Conclusion}

There are many things this essay does not consider, such as the influence of seat allocation formulas and ballot structure (Rae 1971 and Lijphart 1990), vote thresholds (Taagepera and Shugart 1989), the influence of presidential versus parliamentary systems (Jones 1992a,b and Shugart and Carey 1992), and the nature of federal institutions and the territoriality of ethnicity (Horowitz 1991, Lijphart 1977, 1984): And, as we note earlier, we also fail to consider district magnitude itself as an endogenously determined parameter chosen to achieve certain ends in the context of a particular environment (Shamir 1985). To the extent, then, that $H$ influences $D$, our approach probably 
overstates district magnitude's mediating influence while it understates the role of ethnic heterogeneity.

Unfortunately, sorting out the interdependencies among social structure, electoral laws, and outcomes requires a firmer theoretical footing than is available. An empirical investigation uninformed by rigorously derived theoretical relationships is, with that data at hand, unlikely to yield definitive conclusions. Nevertheless, with this caveat in mind, we conclude by portraying the interactive model in graphical terms. Figure 1 graphs the contours of $N V$ against $D$ and $H$ for the expression $N V=3.98+.94^{*} H^{*} \ln (D)-$ - regression number 18 . Notice in particular that if the effective number of ethnic groups is large (if fractionalization is great), the system becomes especially sensitive to district magnitude. But if fractionalization is low, then only especially large average district magnitudes result in any "wholesale" increase in formally organized parties. Finally, if district magnitude equals one, then the party system is relatively "impervious" to ethnic and linguistic heterogeneity -- keeping in mind, of course, that this conclusion rests on data from one source -stable, economically prosperous Western democracies. 
Appendix 1: Regime Data

\begin{tabular}{|c|c|c|c|c|c|}
\hline Country & Year & NV & $\mathbf{F}$ & ENPV & D \\
\hline \multirow[t]{2}{*}{ Australia } & 1940 & 3 & 0.69 & 3.56 & 1.00 \\
\hline & 1987 & 4 & 0.69 & 2.90 & 1.00 \\
\hline \multirow[t]{3}{*}{ Austria } & 1930 & 3 & 0.88 & 3.15 & 5.70 \\
\hline & 1970 & 3 & 0.88 & 2.29 & 5.70 \\
\hline & 1983 & 3 & 0.88 & 2.40 & 20.30 \\
\hline \multirow[t]{2}{*}{ Belgium } & 1939 & 6 & 0.46 & 4.17 & 7.00 \\
\hline & 1987 & 11 & 0.46 & 8.12 & 7.10 \\
\hline \multirow[t]{2}{*}{ Canada } & 1940 & 4 & 0.25 & 2.69 & 1.00 \\
\hline & 1988 & 3 & 0.25 & 3.04 & 1.00 \\
\hline \multirow[t]{4}{*}{ Denmark } & 1939 & 8 & 0.97 & 3.85 & 10.00 \\
\hline & 1953 & 6 & 0.97 & 3.92 & 10.00 \\
\hline & 1968 & 7 & 0.97 & 4.56 & 7.30 \\
\hline & 1988 & 10 & 0.97 & 5.83 & 7.30 \\
\hline \multirow[t]{2}{*}{ Finland } & 1939 & 7 & 0.84 & 4.05 & 14.00 \\
\hline & 1987 & 8 & 0.84 & 6.15 & 14.00 \\
\hline \multirow[t]{4}{*}{ France } & 1946 & 6 & 0.75 & 4.65 & 5.00 \\
\hline & 1956 & 8 & 0.75 & 6.08 & 5.00 \\
\hline & 1981 & 7 & 0.75 & 4.14 & 100 \\
\hline & 1988 & 7 & 0.75 & 4.38 & 1.00 \\
\hline \multirow[t]{3}{*}{ Germany } & 1924 & 10 & 0.98 & 6.51 & 14.10 \\
\hline & 1933 & 7 & 0.98 & 3.83 & 17.00 \\
\hline & 1987 & 5 & 0.98 & 3.56 & 1.99 \\
\hline Greece & 1989 & 3 & 0.91 & 2.73 & 5.30 \\
\hline \multirow[t]{3}{*}{ Iceland } & 1937 & 5 & 0.99 & 3.58 & 1.75 \\
\hline & 1959 & 5 & 0.99 & 3.40 & 1.85 \\
\hline & 1983 & 5 & 0.99 & 4.26 & 6.60 \\
\hline \multirow[t]{2}{*}{ Ireland } & 1938 & 3 & 0.96 & 2.55 & 3.50 \\
\hline & 1989 & 6 & 0.96 & 3.36 & 4.00 \\
\hline \multirow[t]{2}{*}{ Israel } & 1969 & 10 & 0.81 & 3.63 & 120.00 \\
\hline & 1988 & 9 & 0.81 & 5.02 & 120.00 \\
\hline Italy & 1987 & 9 & 0.96 & 4.61 & 20.00 \\
\hline \multirow{3}{*}{$\begin{array}{l}\text { Japan } \\
\text { Luxemburg }\end{array}$} & 1986 & 6 & 0.98 & 3.35 & 4.00 \\
\hline & 1937 & 4 & 0.94 & 3.35 & 6.50 \\
\hline & 1989 & 5 & 0.94 & 4.65 & 15.00 \\
\hline \multirow[t]{2}{*}{ Netherlands } & 1937 & 8 & 0.91 & 5.79 & 100.00 \\
\hline & 1986 & 7 & 0.91 & 3.77 & 150.00 \\
\hline \multirow[t]{2}{*}{ New Zealand } & 1938 & 2 & 0.63 & 2.10 & 1.00 \\
\hline & 1987 & 2 & 0.63 & 2.34 & 1.00 \\
\hline \multirow[t]{3}{*}{ Norway } & 1936 & 8 & 0.96 & 3.75 & 7.90 \\
\hline & 1949 & 6 & 0.96 & 3.76 & 7.90 \\
\hline & 1985 & 7 & 0.96 & 3.63 & 8.20 \\
\hline Portugal & 1987 & 5 & 0.97 & 2.98 & 12.00 \\
\hline \multirow{4}{*}{$\begin{array}{l}\text { Spain } \\
\text { Sweden }\end{array}$} & 1986 & 6 & 0.56 & 3.59 & 6.70 \\
\hline & 1940 & 5 & 0.93 & 2.84 & 8.30 \\
\hline & 1968 & 7 & 0.93 & 3.18 & 9.00 \\
\hline & 1988 & 6 & 0.93 & 3.91 & 12.00 \\
\hline \multirow[t]{2}{*}{ Switzerland } & 1939 & 10 & 0.50 & 6.00 & 7.80 \\
\hline & 1987 & 10 & 0.50 & 6.80 & 8.00 \\
\hline \multirow[t]{2}{*}{ U.K. } & 1935 & 5 & 0.68 & 2.62 & 1.00 \\
\hline & 1987 & 6 & 0.68 & 3.33 & 1.00 \\
\hline \multirow{2}{*}{ U.S.A. } & 1940 & 2 & 0.50 & 2.09 & 1.00 \\
\hline & 1988 & 2 & 0.50 & 2.03 & 1.00 \\
\hline
\end{tabular}


Appendix 2: Election-by-Election Data

$\begin{array}{ccccccc}\text { Country \# } & \text { Date } & \text { ENPV } & \text { ENPS } & \text { NV } & \text { NS } & \text { D } \\ \text { Australia: } & & & & & & \\ 1 & 1919 & 2.43 & 2.40 & 3 & 3 & 1 \\ 1 & 1922 & 2.95 & 2.98 & 3 & 3 & 1 \\ 1 & 1925 & 2.53 & 2.69 & 3 & 3 & 1 \\ 1 & 1928 & 2.74 & 2.85 & 3 & 4 & 1 \\ 1 & 1929 & 2.72 & 2.32 & 3 & 4 & 1 \\ 1 & 1931 & 3.55 & 2.72 & 4 & 4 & 1 \\ 1 & 1934 & 4.11 & 3.31 & 5 & 4 & 1 \\ 1 & 1937 & 3.02 & 2.83 & 4 & 3 & 1 \\ 1 & 1940 & 3.56 & 3.15 & 3 & 3 & 1 \\ 1 & 1943 & 3.09 & 2.04 & 4 & 3 & 1 \\ 1 & 1946 & 2.74 & 2.40 & 4 & 3 & 1 \\ 1 & 1949 & 2.64 & 2.66 & 3 & 3 & 1 \\ 1 & 1951 & 2.49 & 2.57 & 3 & 3 & 1 \\ 1 & 1954 & 2.46 & 2.55 & 4 & 3 & 1 \\ 1 & 1955 & 2.73 & 2.58 & 5 & 3 & 1 \\ 1 & 1958 & 2.97 & 2.59 & 5 & 3 & 1 \\ 1 & 1961 & 2.81 & 2.52 & 5 & 3 & 1 \\ 1 & 1963 & 2.79 & 2.66 & 4 & 3 & 1 \\ 1 & 1966 & 2.98 & 2.63 & 4 & 3 & 1 \\ 1 & 1969 & 2.83 & 2.60 & 4 & 3 & 1 \\ 1 & 1972 & 2.77 & 2.47 & 5 & 3 & 1 \\ 1 & 1974 & 2.66 & 2.52 & 5 & 3 & 1 \\ 1 & 1975 & 2.69 & 2.51 & 4 & 3 & 1 \\ 1 & 1977 & 3.11 & 2.44 & 5 & 3 & 1 \\ 1 & 1980 & 2.81 & 2.64 & 4 & 3 & 1 \\ 1 & 1983 & 2.67 & 2.23 & 4 & 3 & 1 \\ 1 & 1984 & 2.79 & 2.38 & 4 & 3 & 1 \\ 1 & 1987 & 2.90 & 2.28 & 4 & 3 & 1\end{array}$

Austria:

$\begin{array}{rrrrrrr}2 & 1919 & 3.03 & 2.72 & 3 & 2 & 7 \\ 2 & 1920 & 3.10 & 2.69 & 5 & 4 & 7 \\ 2 & 1923 & 2.79 & 2.45 & 4 & 4 & 6 \\ 2 & 1927 & 2.41 & 2.57 & 3 & 4 & 6 \\ 2 & 1930 & 3.15 & 2.78 & 3 & 4 & 6 \\ 2 & 1945 & 2.22 & 2.09 & 3 & 3 & 6 \\ 2 & 1949 & 2.78 & 2.54 & 4 & 4 & 6 \\ 2 & 1953 & 2.76 & 2.48 & 4 & 4 & 6 \\ 2 & 1956 & 2.48 & 2.23 & 4 & 4 & 6 \\ 2 & 1959 & 2.48 & 2.20 & 4 & 3 & 6 \\ 2 & 1962 & 2.47 & 2.19 & 4 & 3 & 6 \\ 2 & 1966 & 2.39 & 2.14 & 3 & 3 & 6 \\ 2 & 1970 & 2.29 & 2.12 & 3 & 3 & 6 \\ 2 & 1971 & 2.28 & 2.21 & 4 & 3 & 20 \\ 2 & 1975 & 2.27 & 2.21 & 4 & 3 & 20 \\ 2 & 1979 & 2.27 & 2.22 & 3 & 3 & 20 \\ 2 & 1983 & 2.40 & 2.26 & 3 & 3 & 20 \\ 2 & 1986 & 2.72 & 2.63 & 3 & 3 & 20\end{array}$

Belgium

$\begin{array}{lllllll}3 & 1919 & 3.33 & 3.04 & 6 & 5 & 7 \\ 3 & 1921 & 3.42 & 3.00 & 6 & 6 & 7 \\ 3 & 1925 & 3.23 & 2.85 & 6 & 6 & 7 \\ 3 & 1929 & 3.48 & 3.21 & 6 & 6 & 7 \\ 3 & 1932 & 3.22 & 2.87 & 5 & 5 & 7 \\ 3 & 1936 & 4.59 & 4.10 & 6 & 6 & 7 \\ 3 & 1939 & 4.17 & \mathbf{3 . 7 5} & 6 & 6 & 7 \\ 3 & 1946 & 3.28 & 2.91 & 4 & 4 & 7\end{array}$




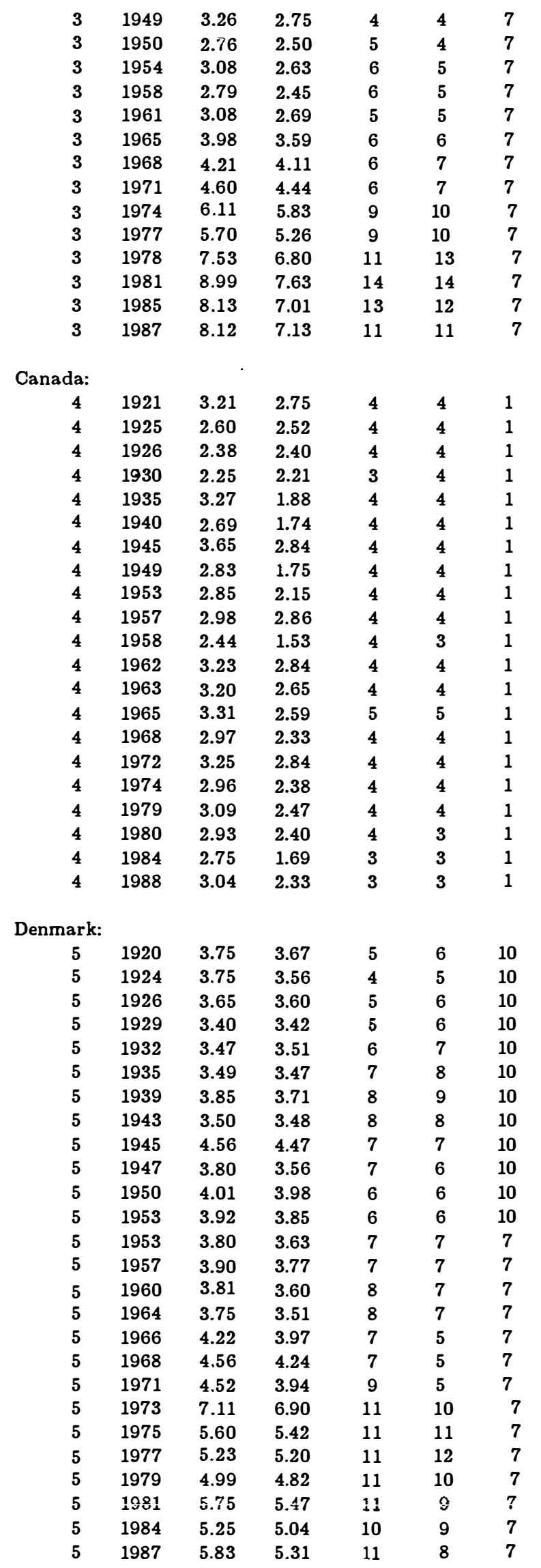


Finland:

$\begin{array}{lllllll}6 & 1919 & 4.18 & 3.96 & 6 & 5 & 14 \\ 6 & 1922 & 5.46 & 5.24 & 6 & 6 & 14 \\ 6 & 1924 & 5.14 & 4.92 & 6 & 6 & 14 \\ 6 & 1927 & 5.08 & 4.69 & 6 & 6 & 14 \\ 6 & 1929 & 5.02 & 4.46 & 7 & 6 & 14 \\ 6 & 1930 & 4.18 & 3.94 & 6 & 6 & 14 \\ 6 & 1933 & 4.23 & 4.00 & 6 & 7 & 14 \\ 6 & 1936 & 4.28 & 3.71 & 7 & 7 & 14 \\ 6 & 1939 & 4.05 & 3.50 & 7 & 7 & 14 \\ 6 & 1945 & 5.09 & 4.77 & 7 & 6 & 14 \\ 6 & 1948 & 4.90 & 4.54 & 6 & 6 & 14 \\ 6 & 1951 & 4.96 & 4.78 & 6 & 6 & 14 \\ 6 & 1954 & 4.98 & 4.71 & 6 & 6 & 14 \\ 6 & 1958 & 5.19 & 4.87 & 7 & 7 & 14 \\ 6 & 1962 & 5.86 & 5.09 & 7 & 7 & 14 \\ 6 & 1966 & 5.22 & 4.96 & 7 & 8 & 14 \\ 6 & 1970 & 6.17 & 5.58 & 9 & 8 & 14 \\ 6 & 1972 & 5.95 & 5.51 & 8 & 8 & 14 \\ 6 & 1975 & 5.89 & 5.31 & 9 & 8 & 14 \\ 6 & 1979 & 5.74 & 5.21 & 9 & 8 & 14 \\ 6 & 1983 & 5.45 & 5.14 & 8 & 8 & 14 \\ 6 & 1987 & 6.15 & 5.00 & 8 & 8 & 14\end{array}$

France:

\begin{tabular}{|c|c|c|c|c|c|}
\hline 7 & 1945 & 4.61 & 4.20 & 5 & 5 \\
\hline 7 & 1946 & 4.51 & 4.15 & 5 & 5 \\
\hline 7 & 1946 & 4.65 & 4.32 & 6 & 6 \\
\hline 7 & 1951 & 5.40 & 5.92 & 6 & 6 \\
\hline 7 & 1956 & 6.08 & 5.73 & 8 & 6 \\
\hline 7 & 1958 & 6.08 & 3.44 & 8 & 6 \\
\hline 7 & 1962 & 4.92 & 3.43 & 8 & 8 \\
\hline 7 & 1967 & 4.55 & 3.77 & 7 & 7 \\
\hline 7 & 1968 & 4.32 & 2.49 & 7 & 6 \\
\hline 7 & 1973 & 5.68 & 4.53 & 7 & 6 \\
\hline 7 & 1978 & 5.08 & 4.19 & 8 & 6 \\
\hline 7 & 1981 & 4.14 & 2.68 & 7 & 6 \\
\hline 7 & 1986 & 4.66 & 3.90 & 8 & 7 \\
\hline 7 & 1988 & 4.38 & 3.07 & 7 & 7 \\
\hline
\end{tabular}

Germany:

$\begin{array}{ccccccc}8 & 1919 & 4.29 & 4.10 & 6 & 8 & 12 \\ 8 & 1920 & 6.73 & 6.61 & 9 & 10 & 13 \\ 8 & 1924 & 7.58 & 7.11 & 11 & 12 & 14 \\ 8 & 1924 & 6.51 & 6.23 & 10 & 12 & 14 \\ 8 & 1928 & 6.66 & 6.13 & 10 & 13 & 14 \\ 8 & 1930 & 7.28 & 7.10 & 10 & 14 & 15 \\ 8 & 1932 & 4.40 & 4.30 & 7 & 13 & 16 \\ 8 & 1932 & 4.94 & 4.79 & 7 & 12 & 15 \\ 8 & 1933 & 3.83 & 3.73 & 7 & 11 & 17 \\ 8 & 1949 & 5.60 & 4.65 & 9 & 7 & 2 \\ 8 & 1953 & 4.20 & 3.64 & 9 & 6 & 2 \\ 8 & 1957 & 3.58 & 3.07 & 6 & 5 & 2 \\ 8 & 1961 & 3.50 & 3.11 & 5 & 4 & 2 \\ 8 & 1965 & 3.15 & 2.93 & 6 & 4 & 2 \\ 8 & 1969 & 3.02 & 2.71 & 5 & 4 & 2 \\ 8 & 1972 & 2.86 & 2.79 & 4 & 4 & 2 \\ 8 & 1976 & 2.91 & 2.86 & 4 & 4 & 2 \\ 8 & 1980 & 3.10 & 2.96 & 5 & 4 & 2 \\ 8 & 1983 & 3.21 & 3.16 & 5 & 5 & 2 \\ 8 & 1987 & 3.50 & 3.47 & 5 & 5 & 2\end{array}$


Greece:

$\begin{array}{lllllll}9 & 1974 & 2.74 & 1.73 & 4 & 5 & 5 \\ 9 & 1977 & 3.74 & 2.32 & 4 & 5 & 5 \\ 9 & 1981 & 2.68 & 2.10 & 4 & 3 & 5 \\ 9 & 1985 & 2.59 & 2.14 & 4 & 3 & 5 \\ 9 & 1989 & 2.73 & 2.40 & 3 & 3 & 5\end{array}$

Iceland:

$\begin{array}{lllllll}10 & 1916 & 4.56 & 4.78 & 6 & 3 & 2 \\ 10 & 1919 & 3.05 & 2.96 & 4 & 2 & 2 \\ 10 & 1922 & 4.28 & 3.01 & 4 & 2 & 2 \\ 10 & 1923 & 2.59 & 2.12 & 3 & 3 & 2 \\ 10 & 1926 & 3.58 & 3.01 & 4 & 3 & 2 \\ 10 & 1927 & 3.23 & 2.73 & 4 & 3 & 1 \\ 10 & 1930 & 2.68 & 1.80 & 3 & 2 & 1 \\ 10 & 1931 & 2.88 & 2.19 & 4 & 3 & 1 \\ 10 & 1933 & 3.03 & 2.58 & 4 & 3 & 1 \\ 10 & 1934 & 3.55 & 3.27 & 5 & 4 & 2 \\ 10 & 1937 & 3.58 & 3.30 & 5 & 5 & 2 \\ 10 & 1942 & 3.54 & 3.16 & 5 & 4 & 2 \\ 10 & 1942 & 3.65 & 3.49 & 5 & 4 & 2 \\ 10 & 1946 & 3.58 & 3.60 & 4 & 4 & 2 \\ 10 & 1949 & 3.56 & 3.47 & 4 & 4 & 2 \\ 10 & 1953 & 4.16 & 3.44 & 5 & 4 & 2 \\ 10 & 1956 & 3.62 & 3.48 & 5 & 4 & 2 \\ 10 & 1959 & 3.66 & 3.44 & 5 & 4 & 7 \\ 10 & 1959 & 3.40 & 3.20 & 5 & 4 & 2 \\ 10 & 1963 & 3.37 & 3.33 & 4 & 4 & 7 \\ 10 & 1967 & 3.77 & 3.55 & 5 & 5 & 7 \\ 10 & 1971 & 4.10 & 3.85 & 5 & 5 & 7 \\ 10 & 1974 & 3.47 & 3.38 & 5 & 5 & 7 \\ 10 & 1978 & 4.20 & 3.85 & 5 & 4 & 7 \\ 10 & 1979 & 3.89 & 3.79 & 4 & 4 & 7 \\ 10 & 1983 & 4.26 & 4.07 & 5 & 5 & 7 \\ 10 & 1987 & 5.77 & 5.35 & 5 & 5 & 7\end{array}$

Ireland:

$\begin{array}{lllllll}11 & 1922 & 3.84 & 3.21 & 3 & 3 & 4 \\ 11 & 1923 & 3.77 & 3.53 & 4 & 4 & 4 \\ 11 & 1927 & 5.15 & 4.59 & 6 & 6 & 4 \\ 11 & 1927 & 3.42 & 3.14 & 5 & 5 & 4 \\ 11 & 1932 & 2.94 & 2.69 & 4 & 4 & 4 \\ 11 & 1933 & 2.82 & 2.75 & 4 & 3 & 4 \\ 11 & 1937 & 2.90 & 2.61 & 3 & 3 & 4 \\ 11 & 1938 & 2.55 & 2.36 & 3 & 3 & 4 \\ 11 & 1943 & 3.67 & 3.14 & 4 & 4 & 4 \\ 11 & 1944 & 3.24 & 2.74 & 5 & 5 & 4 \\ 11 & 1948 & 3.99 & 3.54 & 6 & 6 & 4 \\ 11 & 1951 & 3.27 & 3.16 & 5 & 5 & 4 \\ 11 & 1954 & 3.21 & 3.03 & 5 & 5 & 4 \\ 11 & 1957 & 3.12 & 2.73 & 6 & 5 & 4 \\ 11 & 1961 & 3.20 & 2.80 & 6 & 5 & 4 \\ 11 & 1965 & 2.72 & 2.63 & 3 & 4 & 4 \\ 11 & 1969 & 2.82 & 2.45 & 3 & 3 & 4 \\ 11 & 1973 & 2.80 & 2.58 & 4 & 3 & 4 \\ 11 & 1977 & 2.73 & 2.37 & 4 & 3 & 4 \\ 11 & 1981 & 2.85 & 2.61 & 4 & 4 & 4 \\ 11 & 1982 & 2.68 & 2.55 & 4 & 4 & 4 \\ 11 & 1982 & 2.71 & 2.55 & 4 & 4 & 4 \\ 11 & 1987 & 3.46 & 2.89 & 6 & 6 & 4 \\ 11 & 1989 & 3.36 & 2.97 & 6 & 6 & 4\end{array}$

Israel:

$\begin{array}{lllllll}12 & 1949 & 5.37 & 5.05 & 8 & 13 & 120 \\ 12 & 1951 & 5.10 & 5.02 & 9 & 13 & 120\end{array}$




$\begin{array}{ccccccc}12 & 1955 & 6.31 & 6.00 & 10 & 11 & 120 \\ 12 & 1959 & 5.15 & 4.90 & 10 & 11 & 120 \\ 12 & 1961 & 5.49 & 5.36 & 9 & 9 & 120 \\ 12 & 1965 & 4.91 & 4.71 & 11 & 11 & 120 \\ 12 & 1969 & 3.63 & 3.56 & 10 & 10 & 120 \\ 12 & 1973 & 3.83 & 3.36 & 8 & 9 & 120 \\ 12 & 1977 & 5.04 & 4.37 & 8 & 9 & 120 \\ 12 & 1981 & 3.59 & 3.12 & 8 & 9 & 120 \\ 12 & 1984 & 4.28 & 3.86 & 10 & 12 & 120 \\ 12 & 1988 & 5.02 & 4.40 & 9 & 10 & 120\end{array}$

Italy:

$\begin{array}{ccccccc}13 & 1946 & 4.67 & 4.39 & 6 & 7 & 20 \\ 13 & 1948 & 2.94 & 2.88 & 7 & 10 & 20 \\ 13 & 1953 & 4.17 & 3.54 & 8 & 9 & 20 \\ 13 & 1958 & 3.87 & 3.45 & 8 & 10 & 20 \\ 13 & 1963 & 4.15 & 3.74 & 8 & 10 & 20 \\ 13 & 1968 & 3.95 & 3.53 & 7 & 7 & 20 \\ 13 & 1972 & 4.07 & 3.55 & 8 & 8 & 20 \\ 13 & 1976 & 3.50 & 3.16 & 9 & 9 & 20 \\ 13 & 1979 & 3.90 & 3.47 & 9 & 11 & 20 \\ 13 & 1983 & 4.51 & 4.11 & 9 & 13 & 20 \\ 13 & 1987 & 4.61 & 4.08 & 9 & 12 & 20\end{array}$

Japan:

$\begin{array}{lllllll}14 & 1946 & 4.32 & 4.19 & 5 & 5 & 9 \\ 14 & 1947 & 4.49 & 3.94 & 5 & 5 & 4 \\ 14 & 1949 & 3.88 & 2.75 & 5 & 6 & 4 \\ 14 & 1952 & 3.41 & 3.04 & 5 & 5 & 4 \\ 14 & 1953 & 4.36 & 3.85 & 5 & 6 & 4 \\ 14 & 1955 & 3.99 & 3.68 & 4 & 5 & 4 \\ 14 & 1958 & 2.23 & 1.98 & 3 & 3 & 4 \\ 14 & 1960 & 2.40 & 2.00 & 4 & 4 & 4 \\ 14 & 1963 & 2.55 & 2.15 & 4 & 4 & 4 \\ 14 & 1967 & 3.03 & 2.41 & 5 & 5 & 4 \\ 14 & 1969 & 3.36 & 2.49 & 5 & 5 & 4 \\ 14 & 1972 & 3.40 & 2.67 & 5 & 5 & 4 \\ 14 & 1976 & 4.01 & 3.18 & 6 & 6 & 4 \\ 14 & 1979 & 3.76 & 3.30 & 6 & 6 & 4 \\ 14 & 1980 & 3.44 & 2.71 & 6 & 6 & 4 \\ 14 & 1983 & 3.63 & 3.23 & 6 & 7 & 4 \\ 14 & 1986 & 3.35 & 2.57 & 6 & 7 & 4\end{array}$

Luxemburg:

$\begin{array}{ccccccc}15 & 1919 & 3.01 & 2.69 & 0 & 4 & 12 \\ 15 & 1925 & 4.17 & 3.65 & 4 & 5 & 12 \\ 15 & 1928 & 2.62 & 2.82 & 4 & 4 & 7 \\ 15 & 1931 & 3.44 & 2.97 & 4 & 2 & 7 \\ 15 & 1934 & 3.48 & 3.20 & 4 & 3 & 7 \\ 15 & 1937 & 3.35 & 2.97 & 4 & 3 & 7 \\ 15 & 1945 & 3.34 & 3.05 & 5 & 3 & 13 \\ 15 & 1948 & 3.24 & 2.70 & 4 & 3 & 7 \\ 15 & 1951 & 2.98 & 3.28 & 4 & 4 & 7 \\ 15 & 1954 & 3.00 & 2.68 & 4 & 4 & 13 \\ 15 & 1959 & 3.26 & 3.14 & 4 & 4 & 13 \\ 15 & 1964 & 3.50 & 3.17 & 4 & 4 & 14 \\ 15 & 1968 & 3.49 & 3.41 & 4 & 4 & 14 \\ 15 & 1974 & 4.26 & 4.05 & 5 & 5 & 15 \\ 15 & 1979 & 4.16 & 3.46 & 6 & 5 & 15 \\ 15 & 1984 & 3.56 & 3.22 & 6 & 5 & 16 \\ 15 & 1989 & 4.65 & 3.77 & 5 & 5 & 15\end{array}$

Netherlende:

$\begin{array}{lllllll}16 & 1918 & 5.83 & 5.86 & 9 & 9 & 100\end{array}$

$\begin{array}{lllllll}16 & 1922 & 5.80 & 5.17 & 9 & 9 & 100\end{array}$ 


$\begin{array}{ccccccc}16 & 1925 & 5.80 & 5.25 & 9 & 10 & 100 \\ 16 & 1929 & 5.56 & 5.35 & 8 & 10 & 100 \\ 16 & 1933 & 6.18 & 5.95 & 8 & 11 & 100 \\ 16 & 1937 & 5.79 & 5.19 & 8 & 9 & 100 \\ 16 & 1946 & 4.68 & 4.47 & 7 & 7 & 100 \\ 16 & 1948 & 4.98 & 4.68 & 8 & 8 & 100 \\ 16 & 1952 & 4.99 & 4.65 & 8 & 8 & 100 \\ 16 & 1956 & 4.26 & 4.07 & 7 & 7 & 150 \\ 16 & 1959 & 4.46 & 4.14 & 8 & 8 & 150 \\ 16 & 1963 & 4.79 & 4.50 & 9 & 10 & 150 \\ 16 & 1967 & 6.20 & 5.71 & 10 & 11 & 150 \\ 16 & 1971 & 7.09 & 6.40 & 13 & 13 & 150 \\ 16 & 1972 & 6.85 & 6.41 & 13 & 13 & 150 \\ 16 & 1977 & 3.96 & 3.70 & 7 & 11 & 150 \\ 16 & 1981 & 4.56 & 4.30 & 9 & 10 & 150 \\ 16 & 1982 & 4.23 & 4.02 & 9 & 10 & 150 \\ 16 & 1986 & 3.77 & 3.49 & 7 & 9 & 150\end{array}$

New Zealand:

$\begin{array}{lllllll}17 & 1919 & 3.54 & 2.34 & 3 & 3 & 1 \\ 17 & 1922 & 3.42 & 2.96 & 3 & 3 & 1 \\ 17 & 1925 & 2.98 & 1.94 & 3 & 3 & 1 \\ 17 & 1928 & 3.52 & 3.44 & 4 & 4 & 1 \\ 17 & 1931 & 2.33 & 2.00 & 3 & 3 & 1 \\ 17 & 1935 & 2.97 & 2.00 & 3 & 3 & 1 \\ 17 & 1938 & 2.10 & 1.86 & 2 & 2 & 1 \\ 17 & 1943 & 2.41 & 2.01 & 2 & 2 & 1 \\ 17 & 1946 & 2.01 & 2.00 & 2 & 2 & 1 \\ 17 & 1949 & 2.03 & 1.96 & 2 & 2 & 1 \\ 17 & 1951 & 2.00 & 1.88 & 2 & 2 & 1 \\ 17 & 1954 & 2.48 & 1.97 & 3 & 2 & 1 \\ 17 & 1957 & 2.31 & 2.00 & 3 & 2 & 1 \\ 17 & 1960 & 2.37 & 1.96 & 3 & 2 & 1 \\ 17 & 1963 & 2.39 & 1.97 & 3 & 2 & 1 \\ 17 & 1966 & 2.61 & 2.02 & 3 & 2 & 1 \\ 17 & 1969 & 2.45 & 1.99 & 3 & 2 & 1 \\ 17 & 1972 & 2.43 & 1.87 & 4 & 2 & 1 \\ 17 & 1975 & 2.55 & 1.87 & 4 & 2 & 1 \\ 17 & 1978 & 2.87 & 2.02 & 4 & 3 & 1 \\ 17 & 1981 & 2.89 & 2.08 & 3 & 3 & 1 \\ 17 & 1984 & 2.99 & 1.98 & 3 & 3 & 1 \\ 17 & 1987 & 2.34 & 1.94 & 2 & 2 & 1\end{array}$

$\begin{array}{ccccccc}\text { Norway: } & & & & & & \\ 18 & 1921 & 4.49 & 4.94 & 6 & 7 & 8 \\ 18 & 1924 & 4.90 & 5.24 & 7 & 8 & 8 \\ 18 & 1927 & 4.05 & 3.77 & 7 & 7 & 8 \\ 18 & 1930 & 4.15 & 4.01 & 6 & 6 & 8 \\ 18 & 1933 & 3.98 & 3.32 & 8 & 8 & 8 \\ 18 & 1936 & 3.75 & 3.19 & 8 & 6 & 8 \\ 18 & 1945 & 4.12 & 3.17 & 6 & 5 & 8 \\ 18 & 1949 & 3.76 & 2.67 & 6 & 5 & 8 \\ 18 & 1953 & 3.53 & 3.09 & 6 & 6 & 8 \\ 18 & 1957 & 3.44 & 2.99 & 7 & 6 & 8 \\ 18 & 1961 & 3.58 & 3.22 & 8 & 6 & 8 \\ 18 & 1965 & 3.90 & 3.51 & 8 & 6 & 8 \\ 18 & 1969 & 3.61 & 3.18 & 7 & 5 & 8 \\ 18 & 1973 & 5.17 & 4.14 & 8 & 6 & 8 \\ 18 & 1977 & 3.85 & 2.97 & 8 & 6 & 8 \\ 18 & 1981 & 3.90 & 3.20 & 8 & 7 & 8 \\ 18 & 1985 & 3.63 & 3.09 & 7 & 6 & 8 \\ & & & & & & \\ \text { Portugal: } & & & & & & \\ 19 & 1975 & 3.66 & 2.95 & 4 & 5 & 12 \\ 19 & 1976 & 4.00 & 3.43 & 5 & 5 & 13\end{array}$




\begin{tabular}{|c|c|c|c|c|c|}
\hline 19 & 1979 & 3.01 & 4.16 & 4 & 7 \\
\hline 19 & 1980 & 2.89 & 4.23 & 4 & 7 \\
\hline 19 & 1983 & 3.73 & 3.41 & 4 & 6 \\
\hline 19 & 1985 & 4.77 & 4.26 & 5 & 7 \\
\hline 19 & 1987 & 2.98 & 2.37 & 5 & 6 \\
\hline \multicolumn{6}{|l|}{ Spain: } \\
\hline 20 & 1977 & 4.29 & 2.92 & 5 & 7 \\
\hline 20 & 1979 & 4.25 & 2.81 & 6 & 9 \\
\hline 20 & 1982 & 3.18 & 2.33 & 7 & 10 \\
\hline 20 & 1986 & 3.59 & 3.02 & 6 & 8 \\
\hline \multicolumn{6}{|l|}{ Sweden: } \\
\hline 21 & 1917 & 4.10 & 3.54 & 6 & 6 \\
\hline 21 & 1920 & 4.40 & 4.00 & 6 & 6 \\
\hline 21 & 1921 & 4.04 & 3.60 & 6 & 6 \\
\hline 21 & 1924 & 3.72 & 3.23 & 6 & 6 \\
\hline 21 & 1928 & 3.88 & 3.53 & 6 & 6 \\
\hline 21 & 1932 & 3.81 & 3.32 & 6 & 6 \\
\hline 21 & 1936 & 3.54 & 3.19 & 5 & 5 \\
\hline 21 & 1940 & 2.84 & 2.51 & 5 & 5 \\
\hline 21 & 1944 & 3.48 & 3.13 & 5 & 5 \\
\hline 21 & 1948 & 3.35 & 3.06 & 5 & 5 \\
\hline 21 & 1952 & 3.28 & 3.09 & 5 & 5 \\
\hline 21 & 1956 & 3.38 & 3.18 & 5 & 5 \\
\hline 21 & 1958 & 3.31 & 3.16 & 5 & 5 \\
\hline 21 & 1960 & 3.25 & 3.12 & 5 & 5 \\
\hline 21 & 1964 & 3.42 & 3.25 & 7 & 7 \\
\hline 21 & 1968 & 3.18 & 2.88 & 7 & 7 \\
\hline 21 & 1970 & 3.48 & 3.31 & 6 & 5 \\
\hline 21 & 1973 & 3.50 & 3.35 & 6 & 5 \\
\hline 21 & 1976 & 3.58 & 3.44 & 6 & 5 \\
\hline 21 & 1979 & 3.63 & 3.49 & 6 & 5 \\
\hline 21 & 1982 & 3.39 & 3.13 & 7 & 5 \\
\hline 21 & 1985 & 3.52 & 3.39 & 6 & 5 \\
\hline 21 & 1988 & 3.91 & 3.67 & 6 & 5 \\
\hline
\end{tabular}

Switzerland:

$\begin{array}{lcccccc}22 & 1883 & 5.99 & 5.26 & 10 & 13 & 8 \\ 22 & 1917 & 3.41 & 2.75 & 5 & 5 & 8 \\ 22 & 1919 & 4.79 & 4.49 & 7 & 7 & 8 \\ 22 & 1922 & 4.83 & 4.53 & 8 & 8 & 8 \\ 22 & 1925 & 4.68 & 4.48 & 7 & 8 & 8 \\ 22 & 1928 & 4.49 & 4.36 & 7 & 8 & 8 \\ 22 & 1931 & 4.44 & 4.38 & 7 & 8 & 8 \\ 22 & 1935 & 5.20 & 4.91 & 10 & 10 & 8 \\ 22 & 1939 & 6.00 & 5.17 & 10 & 9 & 8 \\ 22 & 1943 & 5.14 & 4.80 & 8 & 9 & 8 \\ 22 & 1947 & 5.33 & 4.97 & 8 & 9 & 8 \\ 22 & 1951 & 5.09 & 4.80 & 8 & 9 & 8 \\ 22 & 1955 & 4.99 & 4.71 & 9 & 9 & 8 \\ 22 & 1959 & 5.03 & 4.75 & 9 & 9 & 8 \\ 22 & 1963 & 5.00 & 4.78 & 9 & 9 & 8 \\ 22 & 1967 & 5.54 & 5.13 & 9 & 10 & 8 \\ 22 & 1971 & 6.07 & 5.49 & 10 & 10 & 8 \\ 22 & 1975 & 5.79 & 5.00 & 10 & 12 & 8 \\ 22 & 1979 & 5.50 & 5.10 & 10 & 14 & 8 \\ 22 & 1987 & 6.80 & 5.76 & 10 & 12 & 8\end{array}$

U.K.

$\begin{array}{lllllll}23 & 1918 & 4.07 & 2.90 & 5 & 6 & 1 \\ 23 & 1922 & 3.54 & 2.61 & 4 & 5 & 1 \\ 23 & 1923 & 3.06 & 2.95 & 3 & 4 & 1 \\ 23 & 1924 & 2.75 & 1.92 & 3 & 4 & 1 \\ 23 & 1929 & 2.95 & 2.46 & 3 & 4 & 1\end{array}$




$\begin{array}{lllllll}23 & 1931 & 2.51 & 1.65 & 5 & 7 & 1 \\ 23 & 1935 & 2.62 & 2.15 & 5 & 8 & 1 \\ 23 & 1945 & 2.67 & 2.10 & 4 & 7 & 1 \\ 23 & 1950 & 2.44 & 2.08 & 4 & 4 & 1 \\ 23 & 1951 & 2.13 & 2.05 & 3 & 4 & 1 \\ 23 & 1955 & 2.16 & 2.02 & 3 & 4 & 1 \\ 23 & 1959 & 2.28 & 1.99 & 3 & 3 & 1 \\ 23 & 1964 & 2.53 & 2.06 & 3 & 3 & 1 \\ 23 & 1966 & 2.42 & 2.02 & 3 & 4 & 1 \\ 23 & 1970 & 2.46 & 2.07 & 4 & 5 & 1 \\ 23 & 1974 & 3.13 & 2.25 & 5 & 8 & 1 \\ 23 & 1974 & 3.15 & 2.26 & 5 & 9 & 1 \\ 23 & 1979 & 2.87 & 2.15 & 5 & 9 & 1 \\ 23 & 1983 & 3.46 & 2.09 & 6 & 9 & 1 \\ 23 & 1987 & 3.33 & 2.18 & 6 & 9 & 1 \\ & & & & & & \\ \text { U.S.A. } & & & & & & \\ 24 & 1920 & 2.14 & 1.74 & 4 & 3 & 1 \\ 24 & 1922 & 2.14 & 2.02 & 4 & 4 & 1 \\ 24 & 1924 & 2.11 & 1.99 & 3 & 4 & 1 \\ 24 & 1926 & 2.04 & 2.01 & 3 & 4 & 1 \\ 24 & 1928 & 2.03 & 1.90 & 2 & 3 & 1 \\ 24 & 1930 & 2.10 & 2.01 & 2 & 3 & 1 \\ 24 & 1932 & 2.12 & 1.69 & 3 & 3 & 1 \\ 24 & 1934 & 2.15 & 1.67 & 4 & 4 & 1 \\ 24 & 1936 & 2.11 & 1.58 & 3 & 4 & 1 \\ 24 & 1938 & 2.14 & 1.94 & 2 & 4 & 1 \\ 24 & 1940 & 2.09 & 1.93 & 2 & 4 & 1 \\ 24 & 1942 & 2.09 & 2.04 & 2 & 4 & 1 \\ 24 & 1944 & 2.03 & 1.99 & 2 & 3 & 1 \\ 24 & 1946 & 2.04 & 1.98 & 2 & 2 & 1 \\ 24 & 1948 & 2.06 & 1.92 & 2 & 2 & 1 \\ 24 & 1950 & 2.06 & 2.00 & 2 & 2 & 1 \\ 24 & 1952 & 2.04 & 2.01 & 2 & 2 & 1 \\ 24 & 1954 & 2.01 & 1.99 & 2 & 2 & 1 \\ 24 & 1956 & 2.01 & 1.99 & 2 & 2 & 1 \\ 24 & 1984 & 2.03 & 1.95 & 2 & 2 & 1 \\ 24 & 1958 & 1.98 & 1.82 & 2 & 2 & 1 \\ 24 & 1960 & 2.01 & 1.91 & 2 & 2 & 1 \\ 24 & 1962 & 2.01 & 1.93 & 2 & 2 & 1 \\ 24 & 1964 & 1.97 & 1.77 & 2 & 2 & 1 \\ 24 & 1966 & 2.03 & 1.96 & 2 & 2 & 1 \\ 24 & 1968 & 2.05 & 1.97 & 2 & 2 & 1 \\ 24 & 1970 & 2.04 & 1.94 & 2 & 2 & 1 \\ 24 & 1972 & 2.04 & 1.97 & 2 & 2 & 1 \\ 24 & 1974 & 2.00 & 1.79 & 2 & 2 & 1 \\ 24 & 1976 & 2.02 & 1.79 & 2 & 2 & 1 \\ 24 & 1978 & 2.04 & 1.86 & 2 & 2 & 1 \\ 24 & 1980 & 2.06 & 1.97 & 2 & 2 & 1 \\ 24 & 2.03 & 1.93 & 2 & 2 & 1\end{array}$


Figure 1: Number of Parties

$N U=3.98+.94 H * \ln (D)$

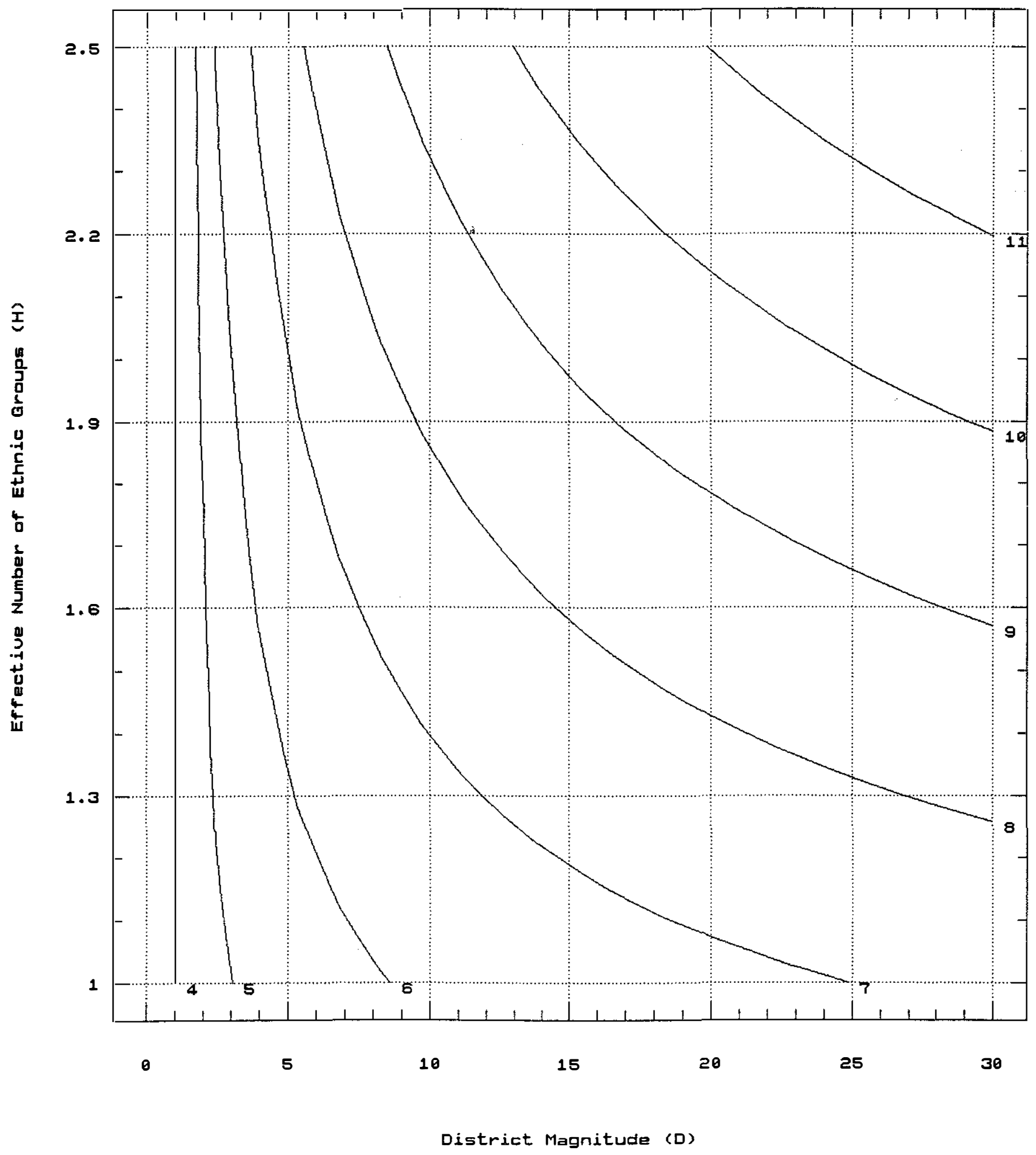




\section{Endnotes}

1. We refer here to the spatial modeling literature (see, for example, Enelow and Hinich 1984) and to the literature on the equilibrium number of parties, beginning with Duverger (1954) and proceeding through Cox (1984), Palf rey (1989) and Fedderson et al (1990).

2. However, for an analysis that takes us part way towards a characterization of other equilibria by way of establishing the existence of other equilibria see Greenberg and Weber (1985).

3. A one-percent cutoff is employed so as to reduce the extent to which our analysis depends on potential variations in the "other" category of vote tabulations. Note that this rule sometimes results in the number of parties with seats in parliaent exceeding the number of parties receiving more than one percent of the vote.

4. Like Lijphart, the central source of our data is Maskie and Rose (1991). We would also like to thank Lijphart for making the data and coding employed in his study available to us.

5. We should comment at this point on one variable that we do not consider -disproportionality. Ignoring normative issues, any concern with disproportionality (as measured by the average of absolute discrepancies between each party's share of the vote and share of legislative seats) derives from the fact that an electoral system's tendency to constrain the number of political parties derives, presumably, from the extent to which its mechanics can produce, ceteris paribus, "wasted votes." Employing measures of disproportionality based on actual election returns as an independent variable, however, ignores the fact that the influence of disproportionality is already reflected in those returns to the extent that they influence voting patterns. Thus, no clean logical relationship can be established between such measures and this study's dependent variable -- number of parties. Instead, we focus on the presumed primary source of disproportionality and the variable that is most commonly subject to choice and manipulation -- district magnitude.

6. See also Lijphart (1977) -- especially the discussion and citations in note 10, page 59 -- and Rae and Taylor (1970) for additional discussion rationalizing the use of fractionalization indices in this context.

7. The particular difficulty with language is that many people are multi-lingual and, thus, their classification in the calculation of a fractionalization index can be arbitrary; similarly, calculating an index of religious fractionalization encounters the problem of how to classify those who indicate either no religious affiliation or classify themselves as agnostic or atheist. 
8. Territoriality also bears on the interactive influence of other institutional features that we do not consider, such as federal structure. A comparison of the United States, Switzerland and Belgium, for example, should result in different conclusions about the role of heterogeneity. All three states are heterogeneous, but territoriality is relevant only in Switzerland and Belgium. Thus, although the degree of federal decentralization will influence the nature of electoral competition and party structures in Belgium and Switzerland, including the ultimate salience of ethnic or linguistic matters, its influence should be less in the United States.

9. Ethnicity data are taken from Atlas Naradov Mira, Moscow, 1960. Religious and linguistic heterogeneity is computed using data from a more recent source - - Encyclopedia Britannica, 1980. Under the reasonable assumption that none of these variables changes greatly for the period under consideration, a single index for ethnicity, for language, and for religion is computed for each country. To our knowledge, this is in fact, they only way to ensure consistent data across time periods.

10. $\operatorname{Ln}(D)$ captures the idea that the vote quota sufficient to secure a seat in parliament, $1 /(D+1)$, decreases as $D$ increases, but at a decreasing rate. Nevertheless, it might seem that a more direct measure would be $1 /(1+D)$ itself. In fact, $\ln (D)$ provides a considerably and consistently better fit to the data than does $.5-1 /(D+1)$. The reasons for this, we can speculate, is that $1 /(D+1)$ approximately equates the influence of $D$ in, say, Austria $(1 / 21=.047)$ with its influence in Israel $(1 / 121=.008)$ when compared to the quota, .5 , in a single-member district system. That is, $1 /(1+D)$ assumes implicitly that there are, in effect, only three types of systems -- "small" ( $D=1)$, "medium" ( $D$ in the rage of, say, 2 to 10), and "large" $(D>10)$. Also, the change in $\ln (D)$ as $D$ increases better matches our sense of the "rate at which a system achieves proportionality" -- .5-1/(D+1) assumes that systems achieve proportionality quickly whereas $\ln (D)$ models a more gradual increase.

11. Taagepera and Shugart (1989:144) report the relationship $E N P V^{\prime}=1.25\left[2+\log \left(D_{\mathrm{e}}\right)\right]$, which, since $\mathrm{D}^{\mathrm{e}}$ varies in the range $[1,75]$, allows us to rewrite this expression as $E N P V^{\prime}=1.25[2+$ $\left..43 \ln \left(D_{\mathrm{e}}\right)\right]$. Rewriting our estimated expression in the same form yields $E N P V=1.25[2.6+$ $.27 \ln (D)]$. Thus, we estimate a higher intercept than does Taagepera and Shugart, but a lower coefficient for district magnitude. This difference, though, can be explained largely by differences in the respective data sets. Specifically, Taagepera and Shugart include pre-World War I data from Sweden, Denmark, the United Kingdom, Norway, and Belgium, as well as data from U.S. Senate races as an observation separate from U.S. House races, all of which have lower than average party counts and district magnitudes. 
12. Of course, performing a non-nested regression by entering $\ln (D), H$, and $H^{*} \ln (D)$ simultaneously generates the usual problem of multicolinearity. Nevertheless, if we do so, there is no increase in adjusted $R^{2}$, the F-statistic declines precipitously as expected, the coefficients on $\ln (D)$ and $H$ are both statistically insignificant, and the coefficient for $H^{*} \ln (D)$ remains significant but less so that in the original single-variable regression.

13. Although we focus on ethnicity, because we have more confidence in its measurement and incorporation into a fractionalization index. Nevertheless, using ENPV and $N V$ as dependent variables, the following regressions parallel regression sets $\{13,14\}$ and $\{17,18\}$ except that language and religious fractionalization are used to calculate heterogeneity -- $H_{1}$ and $H_{\mathbf{r}}$ respectively. First, with respect to linguistic fractionalization,

$$
\begin{aligned}
& E N P V=2.00+.39 \ln (D)+0.9 H_{\mathrm{l}} ; \quad \mathrm{R}^{2}=.21 \\
& \text { (3.0) (3.3) (1.7) } \\
& E N P V=3.23+.29 H_{1}^{*} \ln (D) ; \quad \mathrm{R}^{2}=.19 \\
& \text { (15.3) (3.0) } \\
& N V=2.71+1.0 \ln (D)+1.11 H_{\mathrm{l}} ; \quad \mathrm{R}^{2}=.32 \\
& \text { (2.6) (5.7) (1.4) } \\
& N V=4.36+.68 H_{1}^{*} \ln (D) ; \quad \quad \mathrm{R}^{2}=.34 \\
& \text { (11.9) (5.9) }
\end{aligned}
$$

These regressions show that linguistic heterogeneity generates results that are nearly equivalent to those generated by ethnic heterogeneity with both $R^{2}$ and the magnitude of coefficients being statistically similar. However, if we ignore the issue of whether the differences are statistically significant, ethnicity does provide the better fit. Next, with respect to religious heterogeneity,

$$
\begin{aligned}
& E N P V=\underset{(8.8)}{3.39}+\underset{(3.2)}{.38 \ln (D)}-\underset{(-0.7)}{.08 H_{\mathrm{r}} ;} \quad \mathrm{R}^{2}=.13 \\
& E N P V=3.49+.15 H_{\mathrm{r}}^{*} \ln (D) ; \quad \mathrm{R}^{2}=.12 \\
& \text { (16.4) (2.3) } \\
& N V=4.90+.93 \ln (D)-0.30 H_{\mathrm{r}} ; \quad \mathrm{R}^{2}=.31 \\
& \begin{array}{ll}
(7.9) \quad(5.4) \quad(-1.8) &
\end{array} \\
& N V=5.01+.33 H_{\mathrm{r}}{ }^{*} \ln (D) ; \quad \quad \mathrm{R}^{2}=.19 \\
& \text { (12.5) (2.7) }
\end{aligned}
$$


Thus, religion produces fits that are uniformly inferior to those of language and ethnicity -indeed, in a simple linear model (not reported here), the coefficient on religion has the wrong sign (but is also not significant). This finding, though, is not surprising, if religion is subject to the inherent ambiguity of how people choose to report weak or non-existent affiliations. Thus, we should not suppose that this negative result would hold in societies with more sharply drawn religious affiliations or with affiliations that correlate with ethnicity (e.g., in the successor states of the Soviet Union, especially Ukraine).

14. See, in particular, Tables 12.1 and 12.2 of Taagepera and Shugart's text.

15. $D_{\mathbf{e}}$ provides a better fit than does $D$ since the substitution of $D_{\mathrm{e}}$ for $D$ does appear to adjust the calculation of magnitude in the right direction for the right countries. For example, West Germany has "too many" parties for an average district magnitude of 2 and Denmark has too many for $D=5$. 


\section{References}

Cox, Gary. 1984. "Electoral Equilibrium in Double Member Districts," Public Choice, 44:44351.

Duverger, Maurice. 1954, 1959. Political Parties: Their Organization and Activity in the Modern State (B. North and R. North, trans.) London: Methuen.

Enelow, James and Melvin J. Hinich. 1984. The Spatial Theory of Voting. Cambridge: Cambridge University Press.

Fedderson, Timothy, I. Sened and S.G. Wright. 1990. "Rational Voting and Candidate Entry under Plurality Rule," American Journal of Political Science, 34:1005-16.

Greenberg, Joseph and Shlomo Weber. 1985. "Multiparty Equilibria Under Proportional Representation," technical report no. 456, Institute for Mathematical Studies, Stanford University

Horowitz, Donald L. 1985. Ethnic Groups in Conflict. Berkeley: University of California Press.

Horowitz, Donald L. 1991. A Democratic South Africa?. Cambridge: Cambridge University Press.

Jones, Mark P. 1992a. "The Political Consequences of Electoral Laws in Latin America and the Caribbean," forthcoming, Electoral Studies, winter.

Jones, Mark P. 1992. "Presidential Election Laws and Multipartism in Latin America," mimeo, University of Michigan.

Laver, Michael and Norman Schofield. 1990. Multiparty Government: The Politics of Coalition in Europe. Oxford: Oxford University Press.

Lijphart, Arend. 1977. Democracy in Plural Societies. New Haven: Yale University Press.

Lijphart, Arend. 1984. Democracies: Patterns of Majoritarian and Consensus Government in Twenty-One Countries. New Haven: Yale University Press.

Lijphart, Arend. 1990. "The Political Consequences of Electoral Laws, 1945-85," American Political Science Review, 84 (2): 481-96.

Maskie, T.T. and Richard Rose. 1991. The International Almanac of Electoral History.

Molinar, J. 1991. "Counting the Number of Parties: An Alternative Index," American Political Science Review, 85(4):

Palf rey, Thomas. 1984. "Spatial Equilibrium with Entry," Review of Economic Studies, 51:13956.

Palfrey, Thomas. 1989. "A Mathematical Proof of Duverger's Law," in P.C. Ordeshook, ed. Models of Strategic Choice in Politics, Ann Arbor: University of Michigan Press. 
Rabushka, Alvin and Kenneth Shepsle. 1972. Politics In Plural Societies. Columbus (Ohio): Chas. Merrill Co.

Rae, Douglas. 1967, 1971. The Political Consequences of Electoral Laws, New Haven: Yale University Press.

Rae, Douglas and Michael Taylor. 1970. The Analysis of Political Cleavages. New Haven, Yale University Press.

Riker, William H. 1976. "'The Number of Political parties: A reexamination of Duverger's Law," Comparative Politics, 9:93-106.

Sartori, Giovanni. 1986. "The Influence of Electoral Systems: Faulty Laws or Faulty Method?" in Bernard Grofman and Arend Lijphart, Electoral Laws and Their Political Consequences, New York: Agathon Press.

Shamir, M. 1985. "Changes in Electoral Systems as 'Interventions': Another Test of Duverger's Hypothesis," European Journal of Political Research, 13:1-10.

Shugart, Matthew S. and John M. Carey. 1992. Presidents and Assemblies: Constitutional Design and Electoral Dynamics, Cambridge: Cambridge University Press.

Taagepera, Rein and Matthew S. Shugart. 1989. Seats and Votes: The Effects and Determinants of Electoral Systems. New Haven: Yale University Press. 